\title{
EFEITO DA FORMA FÍSICA DO CONCENTRADO SOBRE A DIGESTIBILIDADE DOS NUTRIENTES EM RAÇÕES PARA EQUINOS
}

\author{
AUGUSTO DE FIGUEIREDO BOMBARDA
}

Orientador: Prof. Dr. ROBERTO T. LOSITO DE CARVALHO

Dissertação apresentada à Escola Superior de Agricultura "Luiz de Queiroz", da Universidade de São Paulo, para obtenção do titulo de Mestre em Agronomia, área de concentração, Nutriçāo Animal e Pastagens.

PIRACICABA

Estado de São Paulo

1989 
B695e Bombarda, Augusto de Figueiredo Concentrado sobre a Digestibili dade dos Nutrientes em Rações para Eqüinos. Pirạcicaba, 1989. $53 p$.

Diss. (Mestre) - ESALQ

Bibliografia.

1. Concentrado na nutrição animal 2. Eqüino Nutrição 3. Ração para eqüino - Digestibili dade

I. Escola Superior de Agricultu ra Luiz de Queiroz, Piracicaba-

$C D D$ 636. 1085 
EFEITO DA FORMA FÍSICA DO CONCENTRADO SOBRE A DIGESTIBILIDADE DE NUTRIENTES EM RAÇð̋ES DE EQUINOS

Augusto de Figueiredo Bombarda

Aprovado em: 20/06/1989

Comissão Julgadora:

$\begin{array}{lll}\text { Prof. Dr. Roberto T. Losito de Carvalho } & \text { ESALQ/USP } \\ \text { Prof. Dr. Cyro Fulvio. Zinsly } & \text { ESALQ/USP } \\ \text { Prof. Dr. José Carlos Nogueira Filho } & \text { FMVZ/USP }\end{array}$

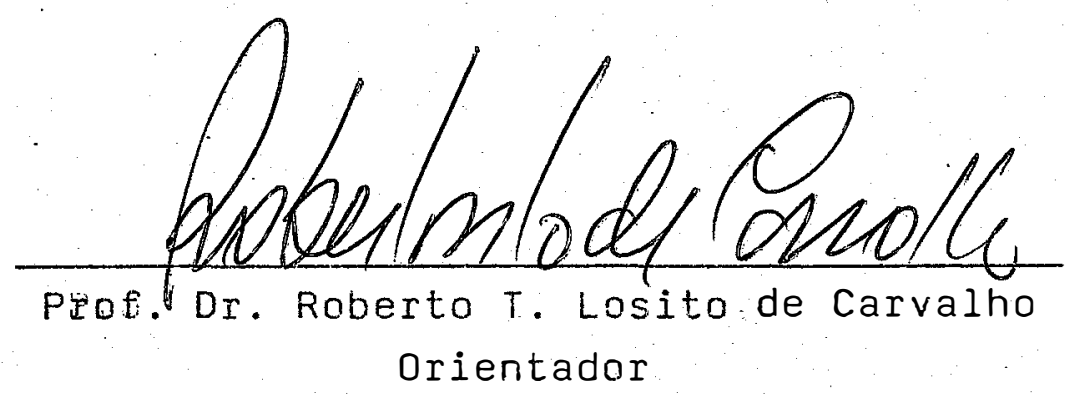


ii.

Aos meus pais

WILSON e DIRCE

pelo apoio, incentivo e compreensão em todas as horas 


\section{AGRADECIMENTOS}

- Prof. Dr. Roberto Thomaz Losito de Carvalho

- Dr. Luiz Roberto Aguiar de Toledo

- Prof. Dr. Hugo Tosi

- Prof. Dr. Irineu Umberto Packer

- Dr. José Felipe de Souza Leão

- Prof. Dr. Josē Fernando Machado Menten

- Srta. Karina Oliveira Vicentini

- Sr. Newton Arruda Neto

- Sra. Marta Leonardt Ribeiro

- Sr. Marcio Arruda

- Sr. Josë Edrardo Silva

- Sr. Melquezedeque

- Sr. Vandico

- Ao Posto de Equinodeocultura de Colina - IZ

- A Rações Guabi S/A

- Ao Laboratório da Divisão de Nutrição Animal e Pastagens do Instituto de Zoctecisia

E a todos aqueles que direta ou indiretamente contribuiram para a realização desse trabalho. 


\section{INDICE}

Pägina

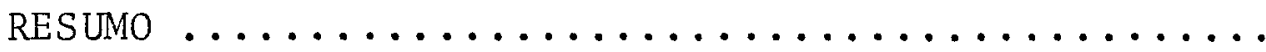

$v i$

SUMMARY $\ldots \ldots \ldots \ldots \ldots \ldots \ldots \ldots \ldots \ldots \ldots \ldots \ldots \ldots \ldots \ldots \ldots \ldots$

viii

1. INTRODUÇAO $\ldots \ldots \ldots \ldots \ldots \ldots \ldots \ldots \ldots \ldots \ldots \ldots \ldots \ldots$

2. REVisAo DE Literatura ................ 03

3. MATERIAL E METODOS ................... 16

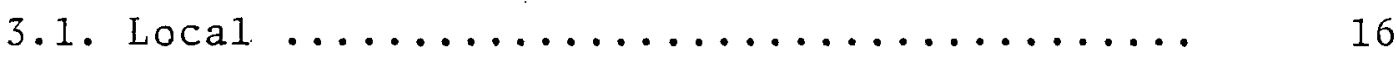

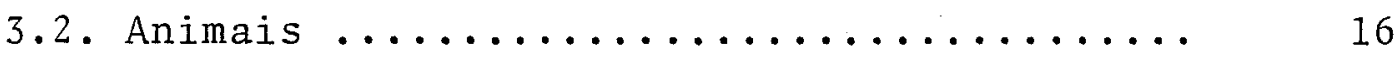

3.3. Instalações $\ldots \ldots \ldots \ldots \ldots \ldots \ldots \ldots \ldots \ldots \ldots$

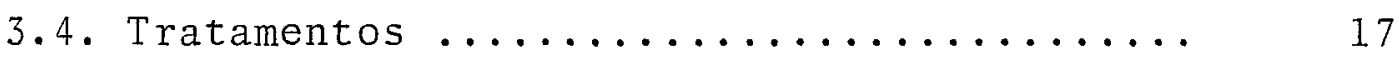

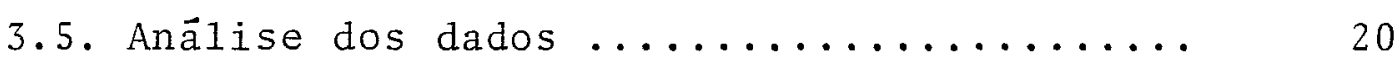

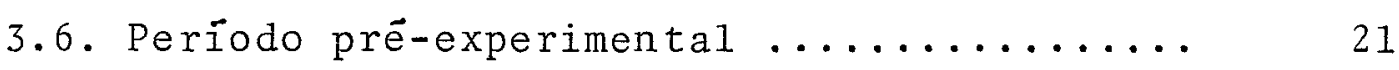

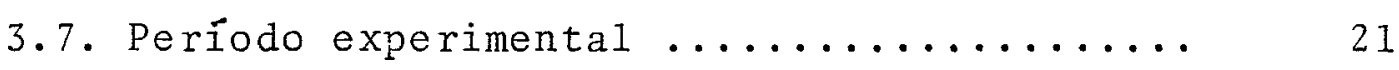

3.8. Anālises químicas ............... 23

4. RESUltados E DISCUSSAO $\ldots \ldots \ldots \ldots \ldots \ldots \ldots \ldots \ldots 24$

4.1. Composição dos alimentos ............ 24

4.2. Ingestão de alimento e excreção fecal .... 26

4.3. Composição química bromatológica das fezes dos animais por tratamento ............

4.4. Ingestão e excreção de matēria seca e dos nutrientes ..................... 29

4.5. Digestibilidade aparente ........... 32

4.5.1. Coeficientes de digestibilidade aparente da matêria seca ............

4.5.2. Coeficientes de digestibilidade aparente da proteína bruta .......... 
4.5.3. Coeficientes de digestibilidade aparente de fibra bruta ............

4.5.4. Coeficientes de digestibilidade aparente do Extrato Etëreo ...........

4.5.5. Coeficientes de digestibilidade aparente do Extrativo Não Nitrogenado .

4.6. Coeficientes de Digestibilidade Indireta (D.I)

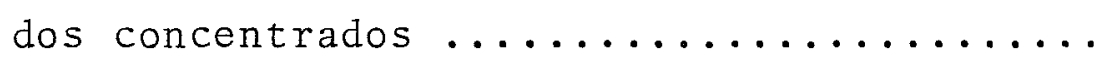

5. CONCLUSOES $\ldots \ldots \ldots \ldots \ldots \ldots \ldots \ldots \ldots \ldots \ldots$ 
EFEITO DA FORMA FISICA DO CONCENTRADO SOBRE A DIGESTIBILIDADE DOS NUTRIENTES EM RAÇOES DE EQUINOS

Autor: Augusto de Figueiredo Bombarda Orientador: Prof. Dr. Roberto T. Losito de Carvalho

\section{RESUMO}

o presente trabalho foi realizado no Posto de Equideocultura de Colina, IZ, CPA, SAA. Seu objetivo foi avaliar o efeito das formas físicas de concentrados na alimentação de equinos em um ensaio de digestibilidade que teve 15 dias de período prë-experimental e 5 dias de período expe rimental. Foram utilizados 16 animais da raça brasileiro de hipismo com idade em torno de 21 meses e peso médio de $330,44 \pm$ $19,73 \mathrm{~kg}$ de peso vivo. As rações oferecidas em razão de $2 \%$ do peso vivo dos animais eram compostas de feno de graminea e concentrado. Os tratamentos consistiram em oferecer concen trado farelado seco e feno (tratamento A); concentrado fareladu umidecido que recebeu $400 \mathrm{ml}$ de ägua por $\mathrm{kg}$ e feno (tra tamento B). e concentrado peletizado e feno (tratamento C) a cada 4 animais. Tambëm foi oferecida uma ração exclusiva de feno visando obter os coeficientes de digestibilidade da ração basal para posterior aplicação do método da digestibilidade indireta. As rações divididas em duas porções semelhan tes eram fornecidas diariamente as 08:00 hs e 18:00 hs. Agua 
e sal mineralizado estavam à disposição dos animais durante todo experimento.

Os coeficientes de digestibilidade aparente das rações foram obtidos utilizando-se o método convencional (coleta total de fezes), obtendo-se os seguintes resultados mëdios: matéria seca $46,06 \pm 4,68 \% ; 47,28 \pm 3,73 \% ;$ e 49,62 \pm $1,32 \%$; proteína bruta $66,90 \pm 3,81 \% ; 65,23 \pm 5,68 \%$; e $70,31 \pm$ $3,49 \%$; fibra bruta $29,11 \pm 7,13 \% ; 31,08 \pm 4,56 \% ;$ e $32,30 \pm$ $1,87 \%$; extrato etëreo $60,68 \pm 7,30 \% ; 58,08 \pm 6,50 \% ;$ e $62,82 \pm$ $3,91 \%$ e extrativo não nitrogenado $52,03 \pm 4,30 \% ; \quad 58,41 \pm$ $2,57 \%$; e 55,07 $\pm 2,23 \%$, respectivamente, para os tratamentos A, B e C. Os coeficientes de digestibilidade indireta dos concentrados obtidos foram para os tratamentos A, B e C respectivamente: matéria seca 43,35 $410,59 \% ; 41,51 \pm 9,87 \%$; e $51,64 \pm 3,06 \% ;$ proteina bruta $77,02 \pm 0,06 \% ; 71,09 \pm 7,89 \% ; \mathrm{e}$ $82,51 \pm 3,86 \% ; f_{\perp}$ bra bruta $-43,77 \pm 30,54 \% ;-35,75 \pm 22,72 \% ;$ $-49,33 \pm 12,75 \%$; extrato etéreo $69,63 \pm 12,14 \% ; 63,23 \pm 11,29 \%$ e $72,24 \pm 5,62 \%$ e extrativo não nitrogenado $54,62 \pm 9,10 \%$; $56,41 \pm 5,46 \%$ e $62,23 \pm 4,81 \%$.

Os resultados obtidos indicaram que não houve diferença significativa $(P>0,05)$ entre as formas fisicas de apresentação dos concentrados tanto para a digestibilidade das rações como para a digestibilidade indireta dos concentrados. Em função disto, os concentrados farelados pro duzidos na propriedade podem apresentar uma diminuição nos cus tos de produção sem apresentar inconvenientes de ordem técni ca. 


\section{EFFECT OF THE PHYSICAL FORM OF CONCENTRATE ABOVE} NUTRIENTS DIGESTIBILITY IN EQUINE RATION

Author: Augusto de Figueiredo Bombarda Adviser: Prof. Dr. Roberto T. Losito de Carvalho

\section{SUPIIARY}

This study was conducted at the Posto de Equi deocultura belonging to IZ, CPA, SAA in Colina, SP. The objective was to assess the effect of the physical forms of concentrates in horse feeding. A digestibility trial was performed with 15 days of adjustement period and 5 days of collection period. Sixteen horses of the Brasileiro de Hipismo breed with about 21 months of age and weighing $330 \pm 20$ kg bodeweight were utilized. The daily feed corresponded to bodeweight and was composed of grass hay and concentrate. The treatments consisted of feeding dry. concentrate in mea1 form plus hay (A), were ( $400 \mathrm{ml}$ water $/ \mathrm{kg})$ concentrate in meal form plus hay (B), and pelleted concentrate plus hay (C). Four horses were alloted to each treament. Another set of four horses received hay only, to allow to obtain its digestibility coefficients and utilization of the indirect digestibility method. The daily feed was divided in two meals, offered at 8.00 and 18:00 hours. Water and minerals were available at al1 times. 
Total collection of feces was made and the apparent digestibility coefficients were: dry matter $46.06 \pm$ $4.68 \%, 40.28 \pm 3.73 \%$ and $49.62 \pm 1.32 \%$; crude protein $66.90 \pm$ $3.81 \%, 65.23 \pm 5.68 \%$ and $70.31 \pm 3.49 \%$; crude fiber $29.11 \pm$ $7.13 \%, 31.08 \pm 4.56 \%$ and $32.30 \pm 1.87 \%$; ether extract $60.68 \pm$ $7.30 \%, 58.08 \pm 6.50 \%$ and $62.82 \pm 3.91 \%$; nitrogen-free extract $52.03 \pm 4.30 \%, 53.42 \pm 2.57 \%$ and $55.07 \pm 2.29 \%$ for treatments $A, B$ and $C$, respectively. The indirect digestibility coefficients of the concentrates in treatments $A, B$ and $C$ were, respectively: dry matter $43.35 \pm 10.59 \%, 41.51 \pm 9,87 \%$, and $61.64 \pm 3.06 \%$; crude protein $77.02 \pm 0.06 \%, 71.09 \pm 7,89 \%$, and $82.51 \pm 3.86 \%$; crude fiber $-43.77 \pm 30.54 \%,-35.75 \pm$ $22.72 \%$, and $-49.33 \pm 12.75 \%$; ether extract $69.63 \pm 12.14 \%$, $63.23 \pm 11.29 \%$ and $72.24 \pm 5.62 \%$ and nitrogen - free extract $54.62 \pm 9.10 \%, 56.41 \pm 5.46 \%$ and $62.23 \pm 4.81 \%$.

The results indicated that there was no significant effect $(P>.05)$ of physical form of the concentrate either on the digestibility of the total feed or on the digestibility of the concentrate. Therefore, the farm production of concentrates in meal form appears to be technically adequate and may result in reduced production cost. 


\section{INTRODUCÃO}

o rebanho equiino nacional é um dos maiores do mundo e a equinocultura vem se tornando uma atividade zootéc nica de importância econômica no país. Comprova este fato o crescente nümero de novos criadores, na sua grande maioria empresārios dos grandes centros, que se filiam às inümeras associações de registro. O enorme contingente de empresärios que se dedicam à exploração de equinos tem contribuído para - desenvolvimento de programas visando racionalizar a produção. Um dos itens de grande importância na racionalização da nossa equinocultura é o relativo à alimentação do cavalo.

Nosso objetivo prätico no presente trabalho foi de verificar se existe influência da forma física dos concen trados na digestibilidade dos nutrientes. Para tanto foram testados concentrados farelado, farelado umidecido e peletizado, utilizando-se a técnica de digestibilidade indireta. Este processo particular de determinação de digestibilidade é aplicāvel aos alimentos que não oferecem volume fisiológico suficiente aos animais ( $\vec{e}$ o caso de alimentos e suplemen tos concentrados). Para aplicação do processo houve necessí 
dade de um quarto "tratamento", com dieta exclusiva de feno.

Nosso propósito é de que, havendo possibilida de, as rações devem ser produzidas nos haras, nos hipödromos, nas hïpicas, etc., a fim de tentar conseguir uma diminuição do custo com alimentação. 


\section{REVISÃO DA LITERATURA}

Os efeitos das formas físicas na digestão dos alimentos por equinos tem sido estudados por diversos autores.

HINTZ \& LOY (1966, trabalharam com cinco pares de cavalos, sendo sete Puro Sangue Inglês e três Quarto de Milha, com idade variando de cinco a dezenove meses de ida de. Estudaram a digestibilidade dos nutrientes na ração cons tituída de 50,0\% de feno de alfafa (Medicago sativa L.); $32,5^{\circ}$ de cevada (Hordeum vulgare, L.); $10,0^{\circ}$ de farelo de trigo; 5, $0^{\circ}$ de melaço; 2,0\% de sebo; 0,5\% de sal, na forma peletizada e na forma farelada. Os coeficientes de digestibilidade encon trados foram, respectivamente: proteina bruta $75,4 \%$ e $76,1 \%$; fibra bruta $33,3 \%$ e $35,4 \%$; extrato etēreo $70,8 \%$ e 64,8\%; extrativo não nitrogenado $79,5 \%$ e $79,2 \%$ para ambas as formas acima citadas. O coeficiente de digestibilidade do extrato etēreo foi significativamente maior para a ração peletizada, mas não diferiu para proteína, fibra e extrativo não nitroge nado. A ração peletizada foi consumida mais rapidamente. A composição quĩmica bromatológica das rações apresentaram: PB 
$17,7 \%$ e $17,0 \%$ FB $15,8 \%$ e $16,5 \%$ FE $4,0 \%$ e $3,6 \%$ ENN $54,2 \%$ e $54,7 \%$; M $8,3 \%$ e $8,2 \%$, para as formas peletizada e farelada. HAENLEIN et alii (1966) trabalharam com seis poneis com idade compreendida entre um e dois anos e peso médio de $130 \mathrm{~kg}$ e seus carneiros adultos castrados com peso mëdio de $75 \mathrm{~kg}$, e durante 28 dias avaliaram a resposta dos animais a três diferentes formas físicas de feno de alfafa. As três formas de apresentação eram semelhantes quanto a sua composição química, porēm diferiram na densidade e tamanho das partículas. O consumo das formas peletizada e "wafer" foram maiores em $17 \%$ e $24 \%$ pelos equinos e $9 \%$ e $13 \%$ nos ovinos em relação à farelada, o que demonstrou diferenças signi ficativas. Os equinos não mostraram diferenças significati vas nos coeficientes de digestibilidade das três formas de feno, exceto para fibra bruta que foi menos digestivel na for ma peletizada. Jä com os ovinos, houveram quedas significativas de digestibilidade para a matéria seca, matéria orgâni ca, proteina bruta e extrativo não nitrogenado quando os an mais recebiam feno peletizado em relação ao farelado e "wafer". Os autores concluíram que a forma física afetou a utilização das rações para equínos e ovinos.

SLADE \& HINTZ (1969) trabalharam com quatro ëguas adultas (très PSI e uma QM) com peso médio de $430 \mathrm{~kg}$ e quatro poneis, fêmeas adultas com peso médio de $135 \mathrm{~kg}$, durante um periodo de 14 dias (nove pré-experimental e cinco de coleta de fezes), compararam a digestibilidade do feno de 
alfafa peletizado e de uma ração completa peletizada constituida de 50\% feno de alfafa; $30 \%$ cevada (planta), 9\% farelo de trigo; $10 \%$ melaço; $1 \%$ sal entre as éguas e as poneis. Não houve diferença significativa no aproveitamento das dietas entre as éguas e as poneis. Para a ração completa os coeficientes de digestibilidade determinados com as ëguas foram: MO $71,7 \% ; \mathrm{PB} 77,3 \%$ FB $38,6 \%$, EE 33,5\%; ENN $80,6 \%$ p para as poneis: MO $72,4 \%$; PB $79,6 \%$; FB $40,9 \%$ EE $27,4 \%$; ENN $81,6 \%$. A ração apresentava a seguinte composição química: MO 91,6:; PB $16,7 \%$ FB $17,8 \%$, EE 2,0\%; ENN 55,1\%; MM 9,9\%; energia 4.436 $\mathrm{kcal} / \mathrm{g}$. Os coeficientes de digestibilidade para o feno de alfafa com as éguas foram: MO $60,4 \%$ PB $74,0 \%$ FB $34,7 \%$, EE $6,4 \%$; ENN 71,5\%; para as poneis: MO 62,5\%; PB 76,2\%; FB 38, $1 \%$; EE 19,0\%; ENN 73,9\%. O feno de alfafa apresentava a seguinte composição química: MO $90,1 \%$; PB 19,7\%; FB $25,2 \%$ EF 1,8\%; ENN 43,4\%; MM 8,4\%; energia $4.371 \mathrm{kcal} / \mathrm{g}$.

WOLTER et alii (1974) estudaram a influência da forma física da forragem na velocidade do trânsito digestivo em seis poneis com peso mëdio de $170 \mathrm{~kg}$ que recebiam 4 a $5 \mathrm{~kg}$ de alimento dividido em duas refeições ao dia. Os an mais foram mantidos em gaiolas de digestibilidade e o método de avaliação foi o de "partículas coloridas". Após 21 dias de adaptação, a cada 4 horas eram coletadas as fezes e, atra vēs da contagem das partículas marcadas, se estabeleceu uma curva de excreção. As três formas de apresentação e respectiva composição eram: feno normal (1ongo) MS 9021\%; FB 31,19\%; 
PB 5,46\%; feno moído, MS 91,19\%; FB 34,96\%; PB 7,06\%; feno peletizado, MS $92,66 \%$ FB 33,70\%; PB 6,79\%. Os autores observaram que para o feno normal (longo) o tempo médio de retenção no trato digestivo foi de 37 horas. Jä para o feno moí do o tempo foi de 26 horas e para o peletizado foi de 31 horas, o que consistiu em diferença significativa $(P<0,05)$ en tre as três mëdias. Os autores tambëm observaram uma variação individual entre os animais, que foi acentuada nas formas fareladas e peletizada.

VEIGA et alii (1974) compararam, em um ensaio de digestibilidade, o mētodo convencional e o do óxido crômi co. Trabalharam com oito machos equinos, sendo quatro "meio sangue Bretão" com peso médio de $398,5 \mathrm{~kg}$ (lote I) e quatro "meio sangue PSI", com peso mëdio de $310,0 \mathrm{~kg}$ (1ote II). 0 período experimental foi de 18 dias, sendo dez dias período de adaptação e oito dias de coleta de fezes. As excreçöes foram colhidas obedecendo dois esquemas: a) coleta em suces sivos períodos de 24 horas e b) coleta total. No método con vencional, o lote I apresentou os seguintes coeficientes de digestibilidade médio da matëria seca $52,7 \pm 0,7 \%$ e $51,9 \pm$ $1,3 \%$; lote II $45,6 \pm 0,5 \%$ e $48,5 \pm 2,4 \%$, para sucessivos períodos de 24 horas e coleta total. Para o método do öxido crômico, os resultados foram: 10te I 48,6 $\pm 1,0 \%$ e 48,8 $0,8 \%$ e no lote II $43,4 \pm 1,3 \%$ e $42,2 \pm 1,2 \%$, para os sucess $\underline{i}$ vos periodos de 24 horas e coleta total, respectivamente. Con cluíram que o "meio sangue Bretão" apresentou maior aprovei- 
tamento da ração e que os valores obtidos pelo mëtodo conven cional foram mais elevados que os conseguidos pelo mëtodo do óxido crômico. A ração apresentava a seguinte composição: MS $88,06 \%$; MO $82,05 \%$; PB 11,04\%; FB 21,01\%; EE 2,89\% e MM $6,01 \%$.

SHURG \& PULSE (1974) trabalharam com vinte animais (éguas e machos castrados adultos) de peso mëdio de $500 \mathrm{~kg}$, determinaram o consumo mëdio diärio e os coeficientes de digestibilidace da matéria seca e proteína bruta de duas rações. Uma constituida de $51_{0}^{\circ}$ feno de centeio mais $49 \%$ de concentrado (Ração I) e a outra de $51 \%$ feno de festuca mais $49 \%$ do mesmo concentrado. As rações eram peletiza das, isoprotëicas e isocalöricas, contendo, aproximadamente, $10,8 \%$ de proteína bruta e $2,4 \% \mathrm{mcal} / \mathrm{kg}$ de energia digestivel. Os animais foram mantidos confinados individualmente por 60 dias, exercitados diariamente e alimentados duas vezes ao dia. Os coeficientes de digestibilidade foram determinados nos ültimos dez dias do experimento, utilizando o óxido crômico como indicador. o consumo diārio médio foi de $7,93 \mathrm{~kg}$ com $19,64 \mathrm{mcal}$ de energia digestivel na ração I e de $7,25 \mathrm{~kg}$ com $19,64 \mathrm{mcal}$ de energia digestivel na ração II. Os coeficientes de digestibilidade determinados na ração I foram: MS 56,01 $\pm 5,64 \% ; \mathrm{PB} 76,17 \pm 2,49 \%$ e na ração II MS $65,95 \pm 4,16 \%$ e PB $70,30 \pm 3,05 \%$.

WOLTER et alii (19.75) estudaram a influência da forma fisica da forragem sobre a sua digestibilidade em 6 
poneis de peso médio de $170 \mathrm{~kg}$ que recebiam $4 \mathrm{~kg}$ de forragem (graminea e um pouco de alfafa) em duas refeições diārias. Os animais foram mantidos em gaiolas metabólicas e foi utili zado o método de coleta total das fezes durante 8 dias, após 3 semanas de adaptação. Durante a semana que precedeu as medidas de digestibilidade, foram coletadas amostras de sangue em três dias consecutivos para determinação das taxas de glicose e A.G.V. séricos. Para as três formas físicas (feno normal, feno moído e feno peletizado), os coeficientes de digestibilidade da matêria seca e da fibra bruta diferiram S.gnificativamente em $(P<0,01)$ e $(P<0,05)$, respectivamen te, das formas peletizada e moída mostrando melhor resultado para o feno normal. Já para a proteína bruta não houve diferenças entre os tratamentos. As taxas de glicose também variaram significativamente entre o feno normal e os peletizado e moído $(P<0,05)$ ja para os A.G.V. sỏ o äcido acêtico da forma moida diferiu dos outros $(\mathrm{P}<0,01)$. A composiÇão do feno normal era: MS $20,21 \%$; FB $31,19 \%$ PB $5,46 \%$; do fe no moído: MS 91,19\%; FB 34,96\%;:PB 7,06\% e do feno peletizado: MS $92,66 \%$ FB $33,70 \%$; PB 6,79\%. Os coeficientes de digestibilidade obtidos foram: feno longo MS 57,81 $\pm 1,7 \div ;$ $\mathrm{FB} 41,31 \pm 5,0 \% ; \mathrm{PB} 52,23 \pm 5,2 \% ;$ feno moído MS 48,92 \pm $5,3 \% ; \mathrm{FB} 31,49 \pm 8,9 \% ; \mathrm{PB} 55,44 \pm 4,8 \%$; feno peletizado MS $43,65 \pm 4,9 \% ; \mathrm{FB} 33,71 \pm 10,1 \% ; \mathrm{PB} 49,44 \pm 8,5 \%$

WOLTER et alii (1976) estudaram o efeito de formas físicas de um alimento completo (farelado ümido, pe- 
letizado e extrudado) na velocidade de trânsito digestivo e digestibilidade em cinco poneis com peso mëdio de $197 \mathrm{~kg}$, man tidos em gaiolas metabólicas. Os animais receberam cada tra tamento alternadamente em períodos de 6 semanas, onde, nas duas primeiras, o alimento era oferecido "ad libitum" para estabelecer a quantidade a ser consumida, que foi oferecida em duas refeições diārias 08:00 a 17:00 hs. Para determinação dos coeficientes de digestibilidade, foi utilizado o método de coleta total de iezes. Para avaliação da velocida de de trânsito, utilizou-se o mëtodo das particulas coloridas. Também foi avaliado a glicose sérica através cie amostras de sangue que foram tiradas antes da refeição, 1 hora e 37 horas depois. Os autores concluĩram que: a ingestão voluntäria das diferentes formas físicas do alimento não diferiu significativamente; tambēm não houve diferença na velocí dade de trânsito digestivo entre os tratamentos e entre os níveis séricos de glicose. A digestibilidade aparente na MS do alimento extrudado $\left(62,68 \frac{0}{0}\right)$ foi significativamente superior $(\mathrm{P}<0,05)$ ao peletizado $\left(59,57^{\circ}\right)$ e ao farelado $\left(58,97^{\circ}\right)$. Para os demais nutrientes, não observaram diferenças signifi cativas .

MANZANO (1977) trabalhou com 14 fêmeas

em crescimento, puras e mestiças da raça ārabe, durante 63 dias e comparou um arraçoamento tradicional (At) com uma ração com pleta peletizada (RCP). As rações eram constituidas de $60 \%$ de feno de alfafa (Medicago sativa L.), 34\% de milho (Zea 
mays L.) e 6: de farelo de soja (Glycine wightii Willd.). Os animais eram arraçoados 3 vezes ao dia nos dois tratamentos. Foram avaliados ganho de peso, conversão alimentar e coefici entes de digestibilidade. O autor concluiu que não houve di ferença $(P>0,05)$ entre os tratamentos para os critërios avaliados e os coeficientes de digestibilidade médios para RCP e AT encontrados foram: MS $(62,89 \%-62,47 \%)$; PB $(67,39 \%-$ $67,75 \%) ; \operatorname{FB}(33,01 \%-36,16 \%) ; \operatorname{EE}(40,41 \%-40,21 \%)$ e ENN $(80,33 \%-80,08 \%)$.

WOLTER et alii (1978) avaliaram a digestibili dade apa.ente e a atividade bioquímica intracecal em poneis que recebiam o mesmo alimento nas formas peletizada, extrudada e semi extrudada (sô a fração de cereais foi tratada) e que apresentaram, respectivamente, a seguinte composição: MS $90,76 \% ; 89,96 \% ; 90,96 \%$; PB $10,62 \% ; 10,34 \% ; 10,18 \% ;$ FB $16,49 \%$; $16,84 \% ; 16,80^{\circ} ;$ Amido $22,69 \% ; 23,74 \% ; 23,31 \%$; Cinzas $8,40 \%$; $7,61 \% ; 8,27 \% ; \mathrm{Ca} 1,28 \% ; 1,15 \% ; 1,34 \% ; \mathrm{P} 0,39 \% ; 0,44 \% ; 0,43 \%$; MO $82,36 \% ; 82,35 \% ; 82,69 \%$. Trabalharam com 6 poneis de 200 $\mathrm{kg}$ de peso médio em gaiolas de digestibilidade que recebiam $3 \mathrm{~kg}$ de alimento por dia em duas refeições e 3 poneis com fís tula cecal que recebiam somente $2 \mathrm{~kg}$ de alimento por dia, tam bêm em duas refeições. O período de adaptação foi de duas semanas e a terceira foi usada para coleta de fezes. Foi uti lizado o método do ôxido crômico. Nos fistulados foram utilizados os métodos de coleta total e lignina, além do óxido crômico. Foram medidos, tambëm, os niveis de glicose e äci- 
do Iäctico, que não apresentaram diferenças significativas. Os autores concluíram que a forma física do alimento tem pouca influência na digestibilidade aparente dos nutrientes, porēm observaram que o alimento peletizado foi superior aos outros significativamente para o aproveitamento de MS, jä para a PB tiveram equivalência entre o peletizado e semi-extrudado, com resultado inferior para o extrudado. Tara a FB a digestibilidade aparente foi superior no alimento semi-extrúdado e se equivaleu para as outras formas. Os autores não observaram diferenças nas digestibilidades parciais obtidas a nivel de ceco para MS, PB e FB e concluíram que o processo de extrusão aumenta o valor energético do alimento.

FORMENTINI et alii (1979) estudaram a viabili dade da utilização de ração completa peletizada com cavalos adultos em trabalho. Foram observadas as seguintes variá veis: controle clínico (ao repouso, tempo de recuperação após um trabalho estandartizado - frequência cārdio respiratōriacontrole de peso, mensuração dos perímetros toráxico e abdominal); exames de laboratórios (hemocromocitométrico, azotemia, glicemia, colesterolemia, ferrograma, atividade enzimātica sérica da ornitina - carbamil-transferase e teste de funcionalidade hepātica. Não foram encontradas quaisquer di ferenças entre a ração tradicional (feno $6,5 \mathrm{~kg}$, aveia 5,5 $\mathrm{kg}$, "Paglia mangiativa" $1,5 \mathrm{~kg}$, premix vitamínico e mineral $100 \mathrm{~g} / \mathrm{dia}$ ) e a peletizada na performance, exame clínico ou exame de laboratório nos animais utilizados. 
HAENLEIN (1980) analisou um levantamento sobre o efeito do processamento no valor nutritivo de dietas para cavalos e relatou que a peletização não afeta muito a digestibilidade das rações de equinos, exceto por um decrëscimo significativo na digestibilidade da fibra bruta, que é mais do que compensado pelo maior consumo voluntário. E pos sível que a diminuição de digestão da fibra bruta seja devido a uma diminuição no tempo de permanência da digesta no in testino. Ainda citou que diversos autores mostraram que a peletização aumenta a velocidade de passagem de feno pel.o trato gastro intestini. 1 dos cavalos e que o conteủdo de ägua nas fezes tambëm aumenta. Quando os nîveis de consumo de fe no peletizado são restringidos a aqueles do feno longo, as di gestibilidades dos nutrientes nas duas formas físicas de feno são iguais. Isso tambëm parece indicar que o aumento de consumo não é causado por uma diminuição de digestibilidade, que, por sua vez, é devida a uma maior velocidade de passagem intestinal; mas sim pode ser devido ao aumento de consumo que causa uma velocidade de passagem maior que por sua vez faz com que a digestibilidade diminua, favorecido pelo reduzido tamanho da partícula.

WOLTER et alii (1980) trabalharam com 2 poneis com fistulas duodenais que receberam o mesmo alimento peletizado e semi-extrudado (só a porção de cereais recebe tratamento). Os animais recebiam $2 \mathrm{~kg}$ de alimento por dia em duas refeições. As amostras para determinação da digestí 
bilidade aparente eram coletadas a cada duas horas após as refeições e a cada hora para determinação de parâmetros bioquímicos. Sob estas condições os autores observaram que as formas físicas provocaram um aumento significativo nos coefi cientes de digestibilidade duodenal da MS,PB e amido. Os vaIores obtidos foram: MS $11,60 \pm 5,64 \%$ e $22,9 \pm 2,55 \% ; \mathrm{PB} 1,46 \pm$ $4,71 \%$ e $9,54 \pm 2,28^{\circ}$ e amido $58,05 \pm 7,6 \%$ e $69,34 \pm 2,28 \%$ para 0 alimento peletizado e semi-extrudado, respectivamente. Para a MS e PB houve diferença significativa entre as formas físicas. Observaram tambëm aumento nos niveis de ácido propiôni co e ācido lático e diminuição do $\mathrm{pH}$ com o alimento extrudado.

WOLTER et alii (1982) trabalharam com seis poneis de $180 \mathrm{~kg}$ de peso médio em gaiolas metabölicas. Os animais recebiam $2 \mathrm{~kg}$ de alimento por dia divididos em duas refeições. Foram oferecidas sucessivamente quatro dietas à base de cereais, a saber: aveia, cevada, milho e trigo em quatro diferentes formas de apresentação: inteiro (íntegro), achatado, triturado e umidecido. A celulose dos tratamentos foi ajustada utilizando-se palha de trigo. O período de adap tação foi de 3 semanas e o de coleta de seis dias, utilizando-se o método de coleta total de fezes. Os autores concluí ram que as formas físicas de apresentação dos alimentos não alteraram a digestibilidade aparente dos mesmos e que tais processos só se justificariam para animais com problemas de mastigação. Tambēm observaram que a aveia apresentou diges- 
tibilidade aparente inferior em relação aos outros cereais, em especial na MS e MO, o que confirma seu menor valor energêtico. A avaliação do âcido lätico e glicose sêricos também não demonstrou diferenças em relação às formas físicas de apresentação dos cereais.

RAINA \& RAGHAVAN (1985) trabalharam com três grupos de seis cavalos adultos cada e compararam um arraçoamento tradicional com ração completa farelada e ração comple ta peletizada. A proporção dos alimentos nas trêj rações era a mesma e estas diferiram na forma física, sendo que a tradicional era composta de grãos inteiros e feno longo. Todos os grupos passaram por um período de adaptação e 20 dias de coleta para cada dieta. Os animais foram mantidos em bäias. Os autores observaram que o consumo de matēria seca foi maior quando os animais receberam alimentação peletiza da, seguido pelos animais que receberam em forma tradicional. O consumo de matéria seca pelos cavalos alimentados com a forma farelada foi o menor. Na ração peletizada houve uma melhora significativa dos coeficientes de digestibilidade pa ra proteína bruta e extrato etêreo, ja ocorrendo o inverso para a fibra bruta. Quanto ao extrativo não nitrogenado, não houve diferença entre as rações.

LEWIS (1985) cita que a peletização aumenta a digestibilidade da proteína bruta em cereais; e que rações peletizadas possuem as seguintes vantagens: conteüdo intesti nal e reduzido, de modo que 20 a $30 \%$ mais alimento peletiza- 
do pode ser consumido do que forragem solta; todas as vitaminas, minerais e suplementos protéicos podem ser adicionados e não se perderão, proporcionando controle preciso da ra ção consumida; peletes são fäceis para serem fornecidos aos cavalos. O aumento da quantidade que pode ser consumida, a diminuição na perda de folhas no consumo e a moagem do volumoso no alimento peletizado são vantagens importantes para cavalos que necessitam comer muito para se manterem bem, par ticularmente cavalos velhos com dentição pobre. O autor cita como desvantagens da utilização de dietas peletizadas uma ocorrência de mastigação de madeira e um aumento no custo do alimento. 


\section{MATERIAL E MÉTODOS}

\subsection{LOCAL}

0 experimento foi conduzido no Posto de Equi deocultura de Colina, unidade experimental do Instituto de Zootecnia, da Coordenadoria da Pesquisa Agropecuäria, Secretaria da Agricultura do Estado de São Paulo, localizado na região norte do estado, distante $409 \mathrm{Km}$ da Capital, com alti tude de 588 metros.

0 município de Colina estâ situado a $20^{\circ} 43^{\prime} 05^{\prime \prime}$ de latitude sul e 48 $32^{\prime} 38^{\prime \prime}$ longitude oeste. Apresenta clima caracterizado por inverno seco e temperatura média de $15,9^{\circ} \mathrm{C}$ (junho) e no mês mais quente (janeiro), de $29,4{ }^{\circ} \mathrm{C}$. A precipitação média anual é de $1376 \mathrm{~mm}$. O período da seca se estende de abril a setembro e a temporada de chuvas vai de outubro a março. 0 solo é latossolo vermelho amarelo, fase arenosa.

\subsection{Animais}

Foram utilizados dezesseis equinos da raça 
Brasileiro de Hipismo (machos) com idades compreendidas entre 20 e 22 meses, nascidos no ano hípico 1982/83.

Todos os animais estavam identificados por mar cação a fogo e foram devidamente vermifugados.

o peso médio e desvio padrão dos animais no início do experimento foi de $330,44 \pm 19,73 \mathrm{~kg}$.

\subsection{InStaLAgões}

Os animais foram alojados em boxes individuais de alvenaria com ärea de $10,5 \mathrm{~m}^{2}$, providos de bebedou ro automätico, cocho para concentrado e volumoso. Não foi utilizado qualquer tipo de cama sobre o piso de cimento durante os períodos pré-experimental e experimental.

\subsection{Tratamentos}

Foram testados três tratamentos:

a - concentrado farelado seco;

B - concentrado farelado umidecido;

C - concentrado peletizado.

A composição dos alimentos utilizados se encontra na Tabela 1 . 
18.

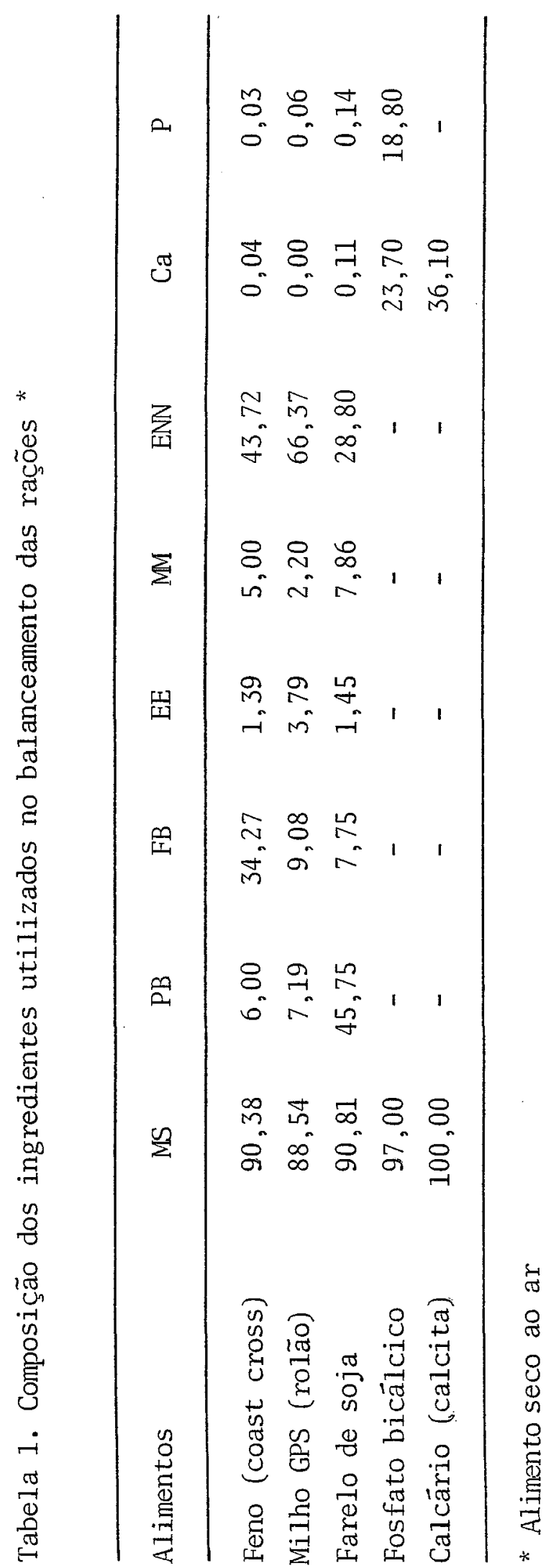


0 umidecimento do tratamento $B$ foi realizado visando eliminar a poeira do alimento seco. Para tanto, foram adicionados $400 \mathrm{ml}$ de água por quilograma de alimento no ato do fornecimento.

o "tratamento $D^{\prime}$ foi realizado para se determinar os coeficientes de digestibilidade do feno da graminea (Cynodon dactylon (L.) Pers. Cv. coast cross) que constituia a dieta basal, coeficientes estes necessários para a determi nação da digestibilidade dos concentrados atravês do processo de Digestibilidade Indireta (D.I.).

A alimentação dos animais foi realizada de acordo com as recomendações do NRC Nutrient Requirements of Horses (1978). Receberam duas refeições ao dia, sendo a pri meira às $08: 00 \mathrm{hs}$ e a segunda às 18:00 hs, onde cada refeição dos tratimentos A, B e C perfazia l: do P.V. dos animais sendo $0,5 \%$ em concentrado e o restante em feno. Jâ para a dieta basal foram oferecidas duas refeições equivalentes de feno. Antes de cada refeição, eventuais sobras da refeição anterior eram recolhidas e pesadas.

A preparação dos concentrados foi realizada na fäbrica de ração do Posto de Equideocultura de Colina. O concentrado farelado produzido precisou sofrer nova moagem para que pudesse ser peletizado em equipamento apropriado. Os cuidados necessārios para evitar que houvesse contaminação do concentrado do tratamento em questão pelo peletizador, foram devidamente tomados, isto é, foi realizado uma limpeza da mâ 
quina e os primeiros $150 \mathrm{~kg}$ do produto peletizado foram desprezados.

O diâmetro do pelete produzido foi de $10 \mathrm{~mm}$, segundo ESMINGER (1973).

O feno de graminea foi produzido no local onde se realizou o experimento e a sua composição acha-se apre sentada na Tabela 1 .

Água e sal mineralizado estavam à disposição dos animais durante todo o experimento.

\subsection{Analise dos Dados}

Os dados foram analisados estatisticamente por ANOVA (PIMENTEL GOMES, 1976). As diferenças entre mëdias de tratamentos foram comparadas pelo teste de DUNCAN. O delineamento experimental utilizado foi inteiramente casualizado com quatro repetições em cada um dos quatro tratamentos e - modelo matemático empregado na análise de variância foi:

$$
Y_{i j}=\mu+T_{(i)}+\varepsilon_{(j j)}
$$

onde: $\quad i=1, \ldots, 4$;

$$
\begin{aligned}
\mu & =\text { média geral; } \\
\mathrm{T}_{(i)} & =\text { efeito do iésimo tratamento; }
\end{aligned}
$$




$$
\begin{aligned}
Y= & \text { digestibilidade aparente geral dos tratamentos; } \\
& \text { digestibilidade aparente associada dos tratamentos; } \\
& \text { digestibilidade aparente geral dos nutrientes; } \\
& \text { digestibilidade aparente associada dos nutrientes; } \\
\varepsilon_{(i j)=} & \text { erro NID }\left(0, \sigma^{2}\right)
\end{aligned}
$$

3.6. Periodo Pré-experimental

Os animais foram mantidos em seus respectivos boxes por quinze dias antes do inicio do período experimental para que se adaptassem ao manejo, instalações e à nova alimentação.

\subsection{Pehioju Experimental}

Esta fase teve duração de cinco dias (MAYNARD et alii, 1979) sob as mesmas condições do período pré-exper $\underline{i}$ menta1.

A coleta total de fezes foi realizada nesta fase do ensaio. Ao final de cada dia era feita a homogeneização e uma alíquota correspondente a $10 \%$ do seu peso era obtida e embalada em sacos plásticos que foram armazenados em um freezer a $-20^{\circ} \mathrm{C}$.

Desse total, após nova homogeneização, foi re tirada uma amostra de 500 gramas para as anālises. 
Os coeficientes de digestibilidade da matëria seca e dos nutrientes) nas rações foram calculados de acordo com a seguinte fórmula (EVANS et alii, 1979):

$$
\text { Digestibilidade }=100 \times \frac{I-E}{I}
$$

onde:

$$
\begin{aligned}
& I=\text { nutriente ingerido; } \\
& E=\text { nutriente excretado }
\end{aligned}
$$

Para a determinação dos coeficientes de Diges tibilidade Indireta (D.I.) onde se calcula a digestibilidade de um alimento volumoso como lastro, no caso o feno de graminea, e a digestibilidade da mistura em quantidades conhecidas do volumoso e do concentrado.

A digestibilidade do concentrado é estabeleci da por diferença segundo CRAMPTON \& HARRIS (1969), onde:

$$
\begin{aligned}
\mathrm{b}= & \text { quantidade do alimento volumoso em } 100 \text { partes da } \\
& \text { mistura; } \\
\mathrm{s}= & \text { quantidade do alimento concentrado em } 100 \text { partes } \\
& \text { da mistura; } \\
\mathrm{b}+\mathrm{s}= & 100 ; \\
\mathrm{B}= & \text { digestibilidade do alimento volumoso em } \frac{\circ}{5} \\
\mathrm{~S}= & \text { digestibilidade do alimento concentrado em } \% ; \\
\mathrm{T}= & \text { digestibilidade da mistura em }:
\end{aligned}
$$


Admitindo-se que não haja efeito associativo so bre a digestibilidade (interação dos alimentos), podemos escrever:

$$
\begin{aligned}
& B \cdot b+S \cdot s=T(b+s) \\
& S \cdot s=T(b+s)-B \cdot b \\
& S=\frac{T(b+s)-B \cdot b}{s}
\end{aligned}
$$

mas, $b=100-2$

portanto: $S=\frac{T \cdot 100-B(100-s)}{S}$

o que nos dâa: $\mathrm{S}=\frac{100(\mathrm{~T}-\mathrm{B})+\mathrm{B}}{\mathrm{s}}$

\subsection{ANALISES QuímicAS}

As análises químicas bromatológicas foram con duzidas no Laboratôrío da Divisão de Nutrição Animal e Pastą gens do Instituto de Zootecnia da Coordenadoria de Pesquisa Agropecuāria, Secretaria da Agricultura do Estado de São Pau 10, Nova Odessa. 


\section{RESULTADOS E DISCUSSÃO}

Existe uma sērie de fatores que afetam a digestão dos equinos: individualidade, composição química dos alimentos, quantidade de alimentos ingeridos, grau de moagem dos alimentos, conteưdo de água, tempo de trânsito dos alimentos atravēs do trato digestivo, quantidade de fibra pre sente na ração e intensidade de trabalho. Quanto ao nível de ingestão, este parece afetar a digestibilidade dos concen trados o que já não ocorre com volumosos e um alimento com granulometria muito fina pode ter diminuição de sua aceitabí lidade.

\subsection{ComposigÃo dos Alimentos}

$\mathrm{Na}$ Tabela 2 são mostrados os resultados das anälises quimicas bromatolögicas dos concentrados e feno uti lizados no trabalho experimental.

Foi balanceado somente um concentrado, sendo que parte do mesmo foi peletizado e notamos que o processo de 
25.

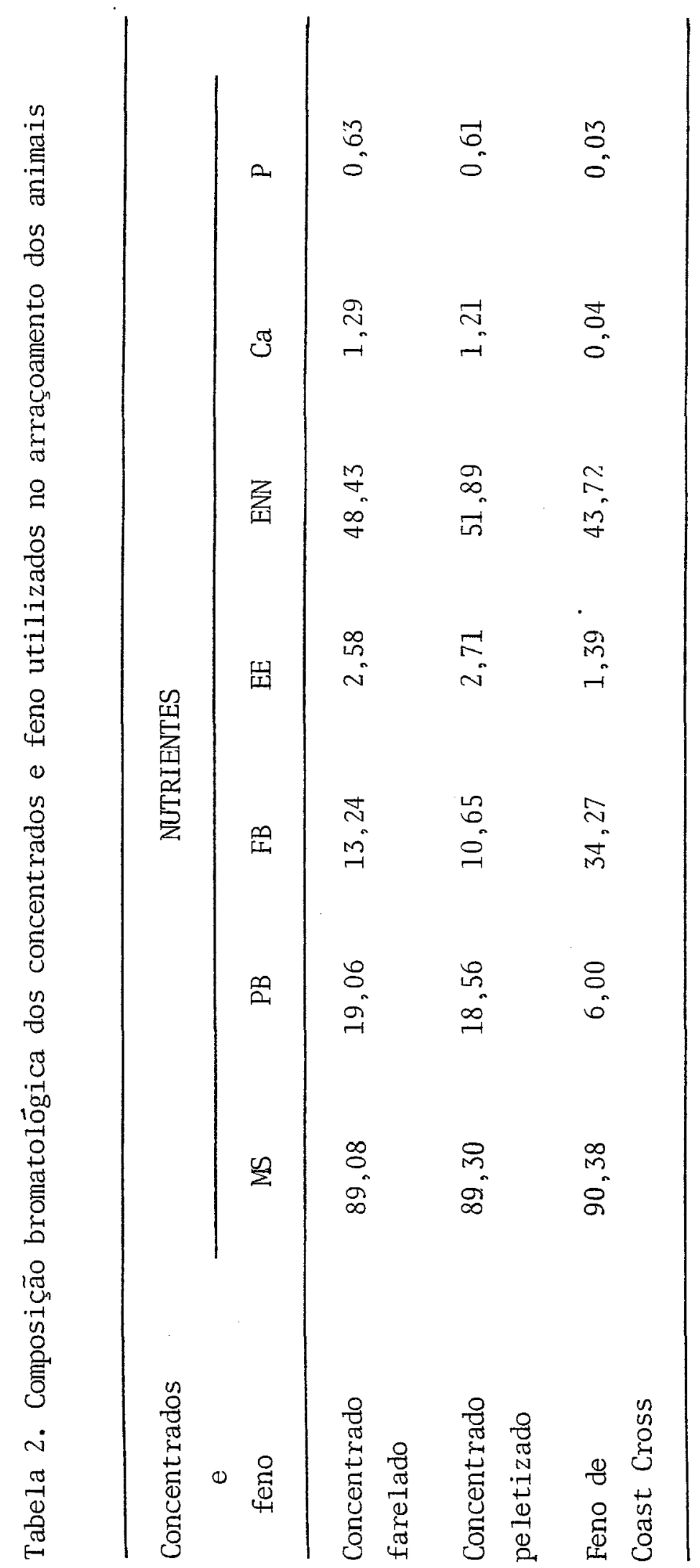


peletização deve ter influenciado nas pequenas diferenças en contradas nas análises, principalmente quanto a fibra bruta. Conforme citado no item Materiais e Métodos, o concentrado utilizado no experimento teve a necessidade de sofrer uma moagem extra para que o processo de peletização pudesse ser realizado. Segundo SCHINEIDER \& FLATT (1975), extrema fine$z a$ de moagem resulta em menores valores para fibra bruta.

os valores encontrados nas anälises mostraram que os concentrados apresentaram quantidades de nutrientes desejāveis para suprir as necessidades dos animais. A anālise do feno indicou que o mesmo è de média qualidade, portanto, apto para alimentação animal.

\subsection{Ingestão de Alimento e Excregã̃o fecal}

Observamos que a ingestão do concentrado pele tizado só ocorreu, a partir do terceiro dia da fase prē-expe rimental, à semelhança do observado p.or NAGATA et alii(1970).

0 consumo de alimentos e a excreção fecal média por cavalo e por tratamento durante os cinco dias da fase experimental encontram-se na Tabela 3 e Figura 1.

Segundo OTT (1979), eqtiinos pesando em torno de $330 \mathrm{~kg}$ de peso vivo (P.V.) e com idade compreendida entre 20 e 22 meses consomem de 1 a $1,5 \%$ de P.V. em concentrado e I a $1,5 \%$ do P.V. em volumoso de alimento seco ao ar (cerca 


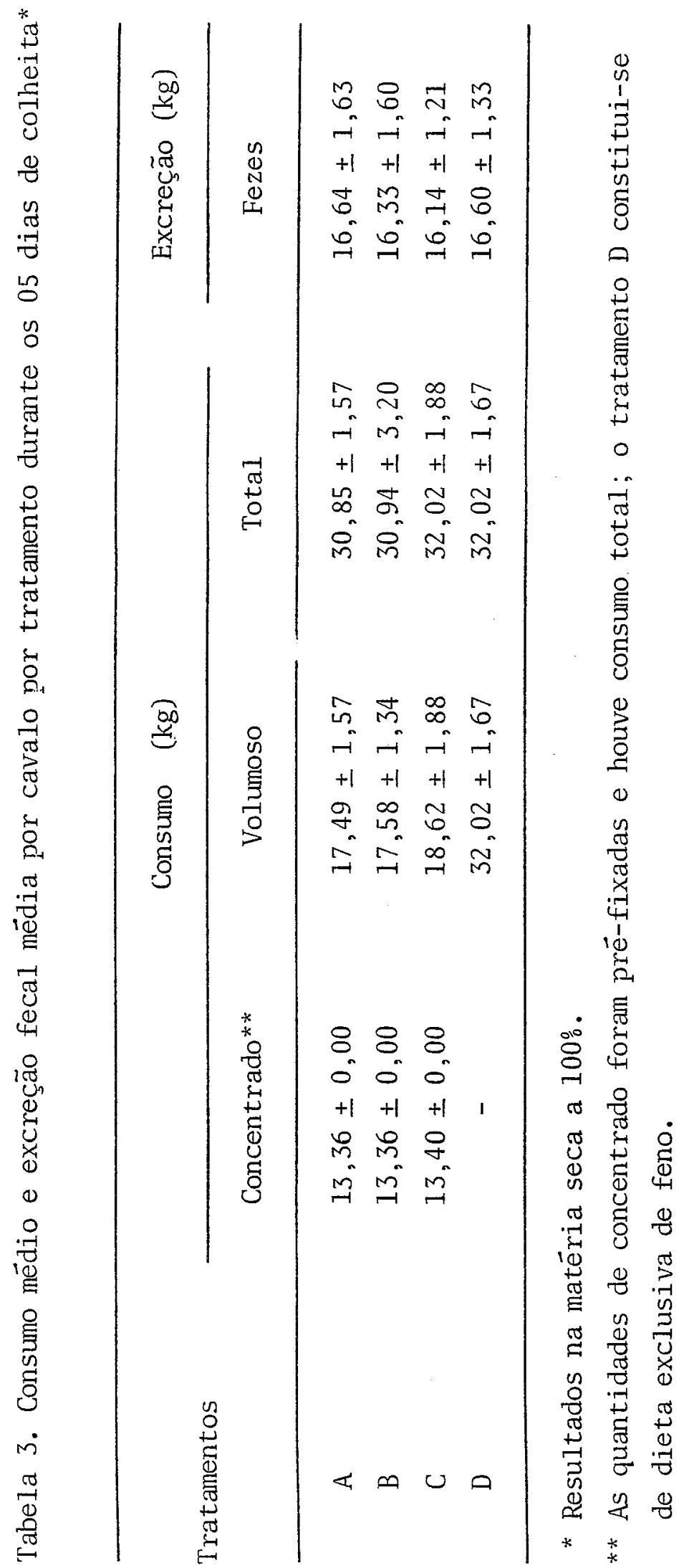




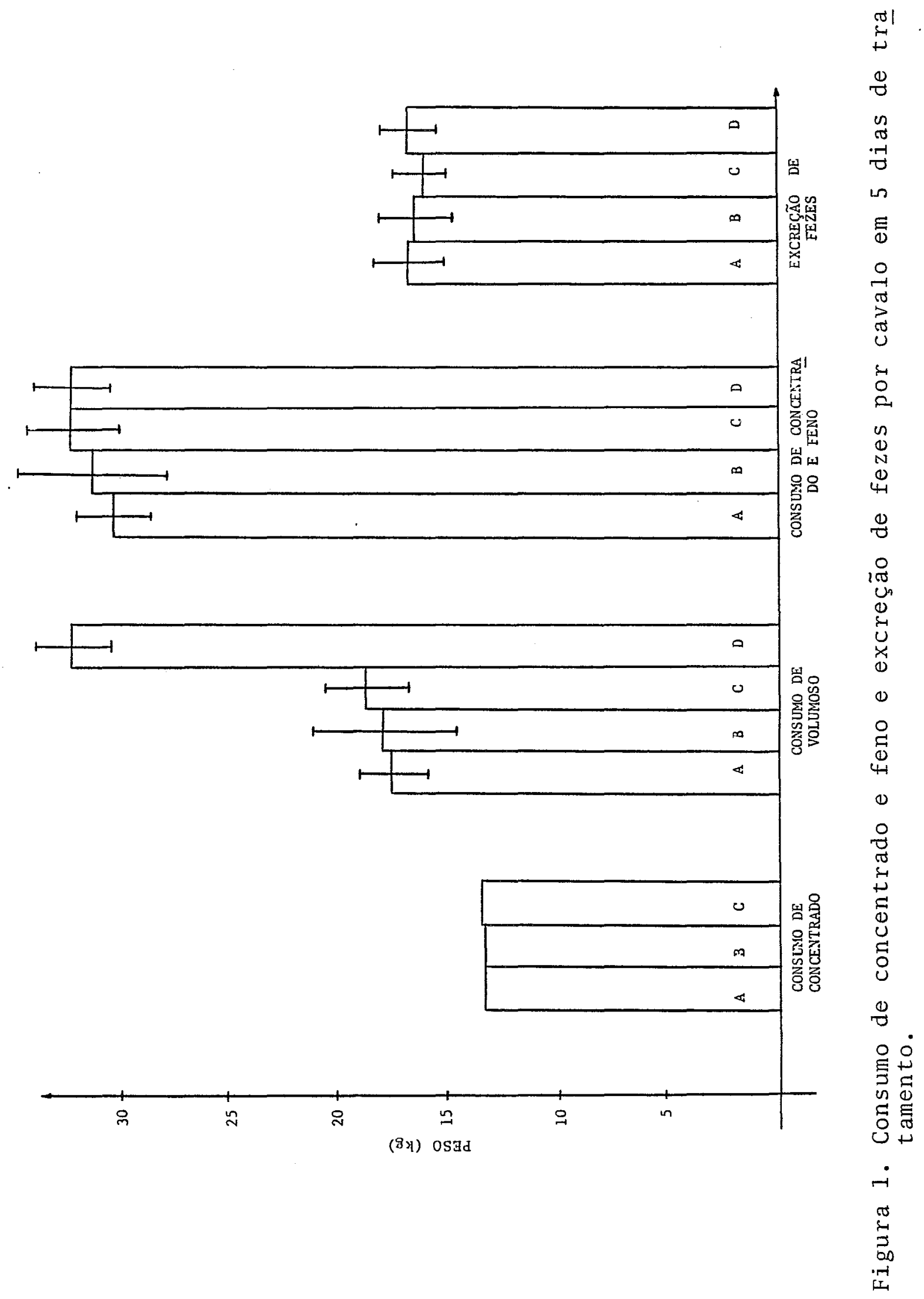


de $90 \%$ da MS), perfazendo um total de 2 a $2,5 \%$ do P.V. (6,6 $\mathrm{kg}$ de alimento total por dia), o que concorda com os dados do experimento.

NAGATA et alii (1970) citam consumo total de alimentos de $2 \%$ do peso corporal ao dia por cabeça para fêmeas Anglo-Ârabe de 303 a 339 kg durante 10 meses.

WOLTER et alii (1975), trabalhando com poneis de $197 \mathrm{~kg}$ de peso vivo em média, forneceram diariamente 2,1\% de alimento na MS deste peso em ensaio de digestibilidade.

\subsection{Composicão Qufmica Bromatológica das Fezes dos ANIMAIS POR TRATAMENTO}

A composição química bromatológica das fezes dos animais por tratamento se encontram na Tabela 4.

\subsection{Ingestão e Excregão de Matéria Seca e dos NUTR I ENTES}

os resultados da ingestão e excreção de matēria seca e dos nutrientes por tratamento durante os 05 dias encontram-se expressos na Tabela 5.

A ingestão e excreção de MS e dos nutrientes comportaram-se conforme o esperado, isto $\vec{e}$, quando houve um 


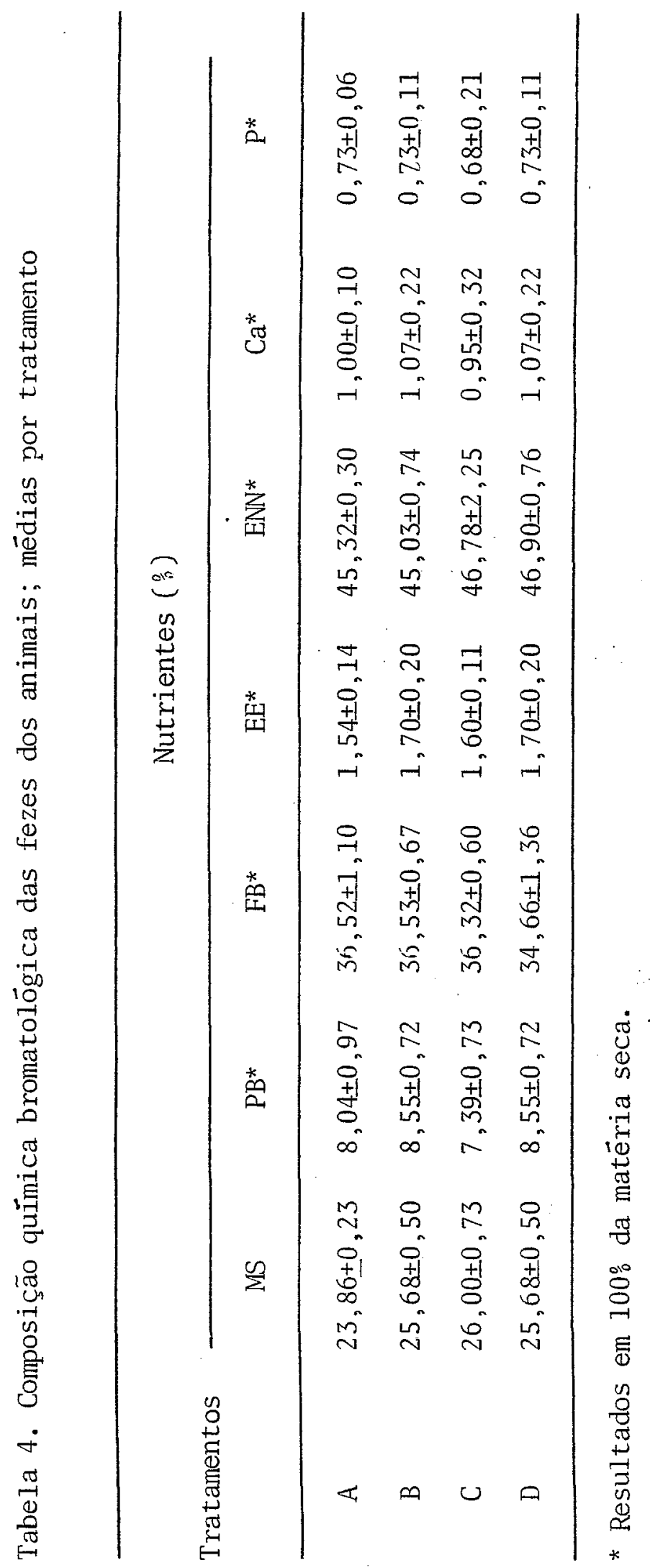




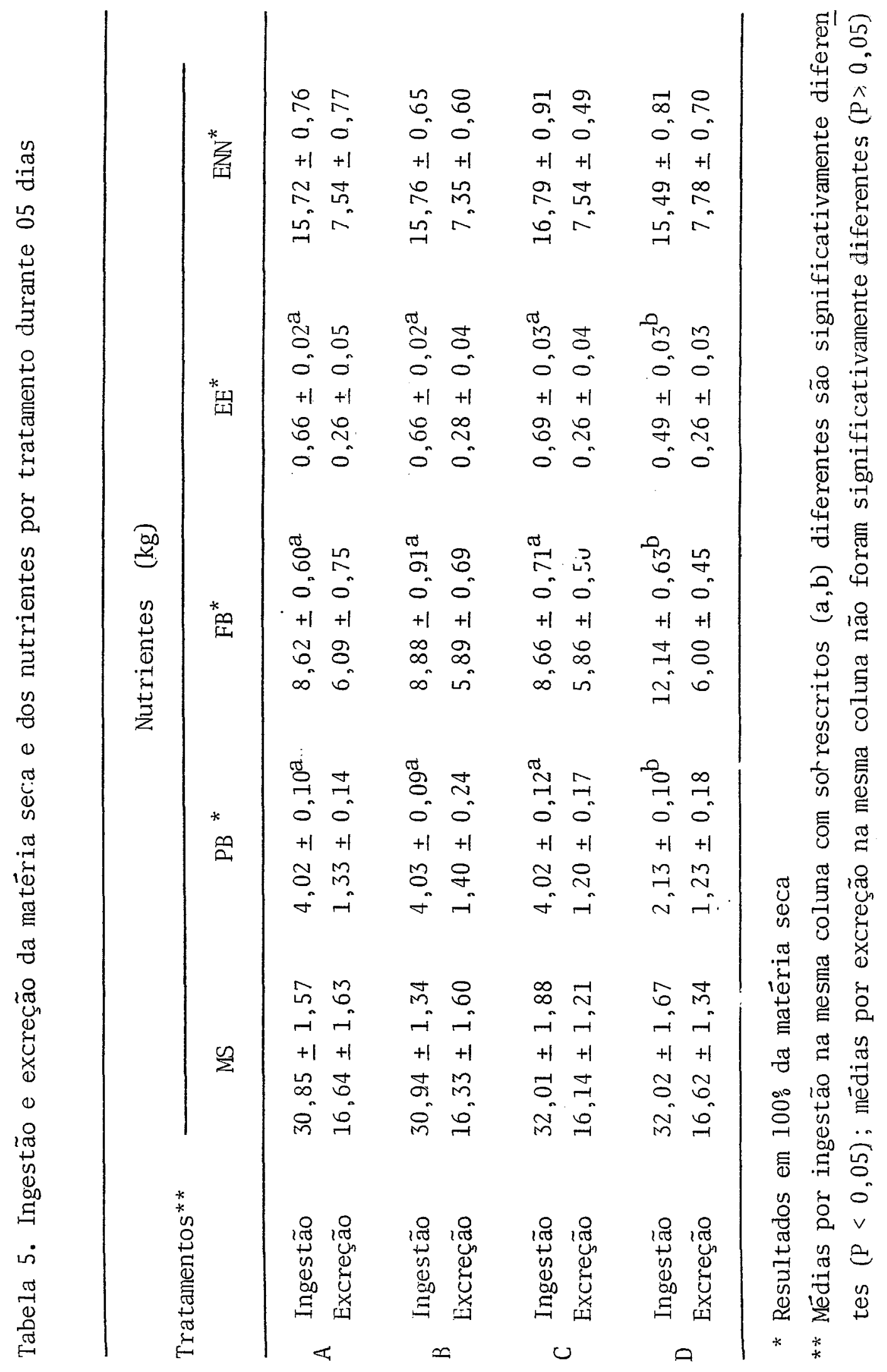


maior fornecimento de um determinado nutriente, PB, FB e EE, a igestão foi maior, e no caso do ENN não ocorreu diferença. Não foi observada diferença significativa $(P<$ 0,05) para excreção de MS e quaisquer nutrientes estudados en tre os tratamentos.

\subsection{Digestibilidade Aparente}

Os coeficientes de digestibilidade aparente da matêria seca e dos nutrientes dos tratamentos encontram-se de monstrados na Tabela 6 e Figura 2. Os dados não apresentaram diferença significativa $(P>0,05)$ entre si para os tratamentos que eram compostos de feno e concentrado.

Vārios fatores podem intervir na determinação dos coeficientes de digestibilidade da matéria seca e dos nu trientes. Os valores encontrados na nossa revisão, oriundos de pesquisas realizadas em países de clima temperado onde os alimentos apresentam características específicas e também países com maior tecnologia na industrialização de rações, às vezes são concordantes com os determinados neste trabalho e, outras vezes, discordantes. Alëm dos fatores enumerados aci ma é tambêm provảvel que as eventuais diferenças encontradas em comparação dos resultados deva-se a outros fatores tais como raças e idades diferentes. 


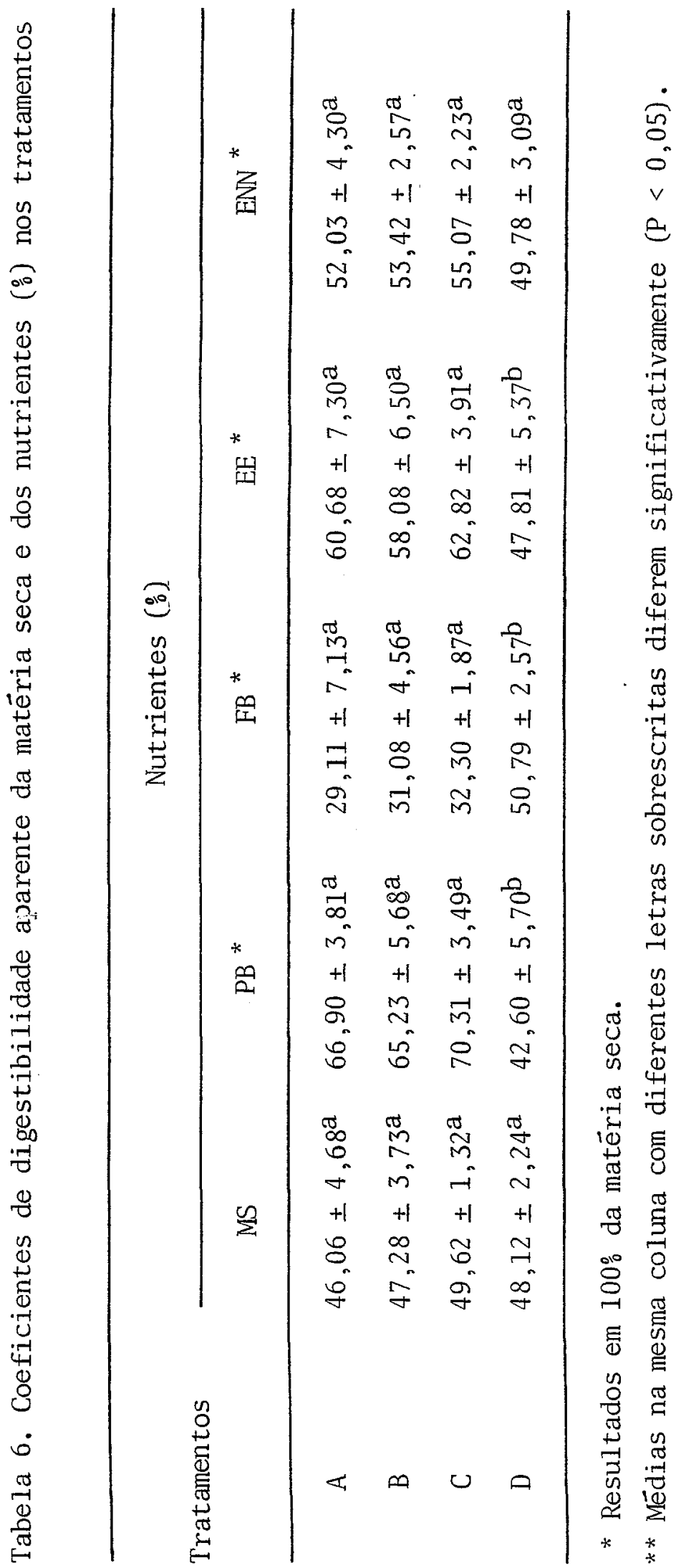



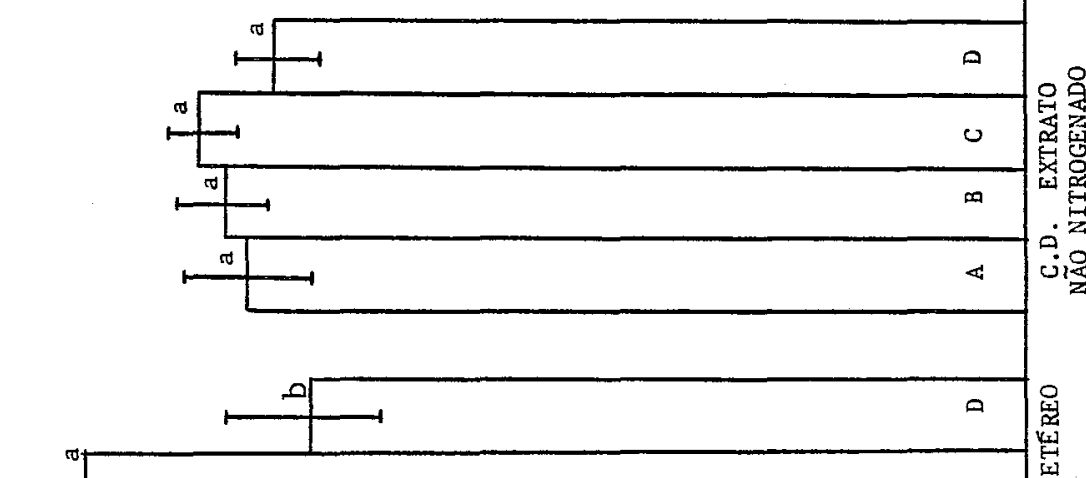

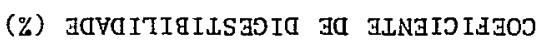


Embora nas tabelas apresentadas neste capitu10 apareçam os resultados dos tratamentos A, B, C e D o tratamento $D \vec{e}$ na verdade uma exigência para a determinação dos coeficientes de digestibilidade indireta. Portanto, as comparações serão realizadas entre os tratamentos A, B e C.

\subsubsection{Coeficientes de Digestibilidade Aparente da Matéria Seca}

Os coeficientes de digestibilidade aparente da matéria seca nas rações foram: Tratamento $A: 46, C) \pm 4,68 \%$; Tratamento B: 47,28 $\pm 3,73 \%$; Tratamento C: $49,62 \pm 1,32 \%$. Não houve diferença significativa $(P>0,05)$ entre os tratamentos.

VEIGA et alii (1974), em animais " $1 / 2$ sangue Bretão" e "l/2 sangue Inglès", determinaram coeficientes de digestibilidade aparente de $51,9 \pm 1,3 \%$ e 43,4 $\pm 1,3 \%$ em rações completas na forma farelada que são próximos aos encontrados neste trabalho. SCHURG \& PULSE (1974) trabalharam cor ração contendo $51 \%$ de feno de centeio mais $49 \%$ de concentrado e encontraram o coeficiente de digestibilidade de 56,08 $5,64 \%$.

MANZANO (1977) trabalhou com a mesma ração cọn pleta nas formas peletizada e farelada e obteve, respectivamente, $62,89 \%$ e $62,47 \%$ de coeficientes de digestibilidade apa 
rente. Estes valores são superiores aos encontrados neste trabalho.

\subsubsection{Coeficientes de Digestibilidade Aparente da Proteina Bruta}

Os coeficientes de digestibilidade aparente

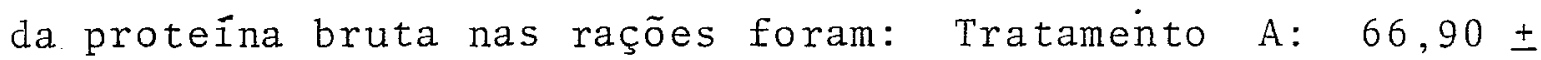
$3,81 \%$; Tratamento $\mathrm{B}: 65,23 \pm 5,68 \%$; Tratamento $\mathrm{C}: 70,31 \pm$ $3,49 \%$. Não houve diferença significativa $(P>0,05)$ entre os tratamentos.

Os dados obtidos neste trabalho para os trata mentos A, B e C são menores que os obtidos por HINTZ \& LOY (1966) que, trabalhando com animais de cinco e dezenove meses de idade, encontraram coeficientes dedigestibilidade apa rente para a proteína bruta de $75,4 \%$ para ração completa peletizada e 76,1\% para a mesma ração farelada. SLADE \& HINTZ (1969), trabalhando com ração completa peletizada em éguas adultas da raça PSI, Quarto de Milha e Poneis, obtiveram 77,3\% de digestibilidade da PB. SCHURG \& PULSE (1974), trabalhando com machos e fêmeas adultos e ração constituída de $51 \%$ de feno de centeio ou $51 \%$ de feno de destuca mais $49 \%$ de concen trado, obtiveram coeficientes de digestibilidade aparente pa ra proteina bruta igual a $76,1 \pm 2,49 \%$ e $70,3 \pm 3,05 \%$ para as respectivas rações. MANZANO (1977), trabalhando com os mesmos ingredientes na forma de arraçoamento tradicional e 
ração completa peletizada, obteve coeficientes de digestibilidade aparente de $67,39 \%$ para a peletizada e 67,75\% para o arraçoamento tradicional, dados estes concordantes com os do presente trabalho.

\subsubsection{Coeficientes de digestibilidade aparente de fibra bruta}

Os coeficientes de digestibilidade aparente da fibra bruta nas rações foram: Tratamento A. 29,11 $\pm 7,13_{0}^{\circ}$; Tratamento B: $31,08 \pm 4,56 \%$ e Tratamento C: $32,20 \pm 1,8: \%$ Os tratamentos não diferiram significativamente $(P>0,05)$ entre si.

Os tratamentos apresentaram coeficientes que estão próximos aos obtidos por HINTz \& LOY (1966) que encontraram 33,3\% para ração completa peletizada e 35,4\% para a mesma ração na forma farelada em animais de cinco a dezenove meses de idade das raças PSI e Quarto de Milha.

Resultados próximos ao deste trabalho foram obtidos por MANZANO (1977) quando trabalhou com a mesma ração completa em duas formas físicas de apresentação com animais em crescimento com sangue de Arabe, a saber: ração pele tizada $33,01 \%$ e ração farelada $36,16 \%$.

Alguns trabalhos apresentaram resultados dife rentes dos obtidos por nös. SLADE \& HINTZ (1969), trabalhan do com éguas adultas das raças PSI, Quarto de Milha e She- 
tland, obtiveram coeficiente de digestibilidade aparente mëdio de $38,6 \%$. RAINA \& RAGAVHAN (1985), trabalhando com cavalos adultos, compararam um arraçoamento tradicional com ra ção completa farelada e ração completa peletizada (a proporção dos alimentos era a mesma nas três rações) e obtiveram coeficientes de digestibilidade para FB de 51,20 $\pm 1,47 \%$, $23,99 \pm 1,76 \%$ e $38,88 \pm 1,57 \%$, respectivamente.

\subsubsection{Coeficientes de digestibilidade aparente do Extrato Etéreo}

Os coeficientes de digestibilidade aparente do extrato etéreo nas rações foram: Tratamento A: 60,68 \pm 7,30\%; Tratamento B: 58,08 $\pm 6,50 \%$ e Tratamento C: $62,82 \pm 3,91 \%$. Os tratamentos não diferiram significativamente $(P>0,05)$ para a digestibilidade aparente do EE.

Os dados obtidos no presente estudo para os tratamentos A, B e C estão pröximos aos encontrados por HINTZ \& LOY (1966) que trabalharam com raças PSI e Quarto de Milha de cinco a dezenove meses de idade com ração completa peletí zada e com a mesma ração na forma farelada, obtendo um coefi ciente de digestibilidade aparente para o extrato etéreo de $70,8 \%$ na forma peletizada e $64,8 \%$ na forma farelada. SLADE \& HINTZ (1969) trabalharam com éguas adultas PSI e Quarto de Mi Iha, com peso médio de $430 \mathrm{~kg}$, obtendo um coeficiente de digestibilidade aparente de $33,5 \%$, que é inferior aos encon- 
trados neste trabalho, assim como os dados de MAZANO (1977), quando comparou um arraçoamento tradicional com ração comple ta peletizada e obteve coeficientes de digestibilidade aparente do EE de 40,41\% e 40,21\%, respectivamente para os dois tratamentos. RAINA \& RAGAVHAN (1985), trabalhando com cavalos adultos e comparando diferentes formas físicas de apresen tação de uma ração, obtiveram para o arraçoamento tradicional coeficiente de digestibilidade aparente do EE de 67,94 \pm $1,89 \%$

\subsubsection{Coeficientes de digestibilidade aparente do Extrativo Não Nitrogenado}

Os coeficientes de digestibilidade aparente do ENN nas rações foram: Tratamento A: 55,03 \pm 4,30\%; Tratamento B: $53,42 \pm 2,57 \%$ e Tratamento C: $55,07 \pm 2,23 \%$. Não hou ve diferença significativa $(P>0,05)$ entre os tratamentos.

HINTZ \& LOY (1966) encontraram $79,5 \%$ para ração completa peletizada e 79,2: para a mesma ração na forma farelada com animais de cinco a dezenove meses de idade das raças PSI e Quarto de Milha. SLADE \& HINTZ (1969), com ração completa peletizada e éguas adultas com peso médio de 430 kg das raças PSI e Quarto de Milha, obtiveram coeficiente de digestibilidade aparente do ENN de 80,6\%.

MANZANO (1977) obteve para uma mesma dieta for necida em arraçoamento tradicional de ração completa peleti- 
$z$ ada em animais com sangue de ārabe $80,08 \%$ e $80,33 \%$, respectivamente. Os dados destes autores se mostraram superiores aos obtidos neste trabalho.

RAINA \& RAGAVHAN (1985), comparando trēs formas de apresentação de uma mesma dieta em cavalos adultos, obtiveram para a ração completa farelada $54,41 \pm 0,77 \%$ para o coeficiente de digestibilidade aparente do ENN. Os resultados destes autores estão próximos aos encontrados no presente estudo.

\subsection{Coeficientes De Digestibilidade Indireta (D.I,) DOS CONCENTRADOS}

Os coeficientes de. J.I. da matéria seca e dos nutrientes dos concentrados encontram-se demonstrados na Tabela 7 e Figura 3 . Os resultados obtidos no presente trabaTho não apresentaram diferença significativa $(\mathrm{P}>0,05)$ entre as formas físicas de apresentação dos concentrados.

Vários autores estudaram o efeito da forma fí sica da ração ou de alimentação em equinos e encontraram resultados que muitas vezes são discordantes. A maior dificuldade para a realização deste experimento foi definir a metodologia necessäria para o estudo dos coeficientes de digestibilidade. Embora na revisão que fizemos não tivëssemos en contrado trabalhos sobre a determinação de digestibilidade in 
41.

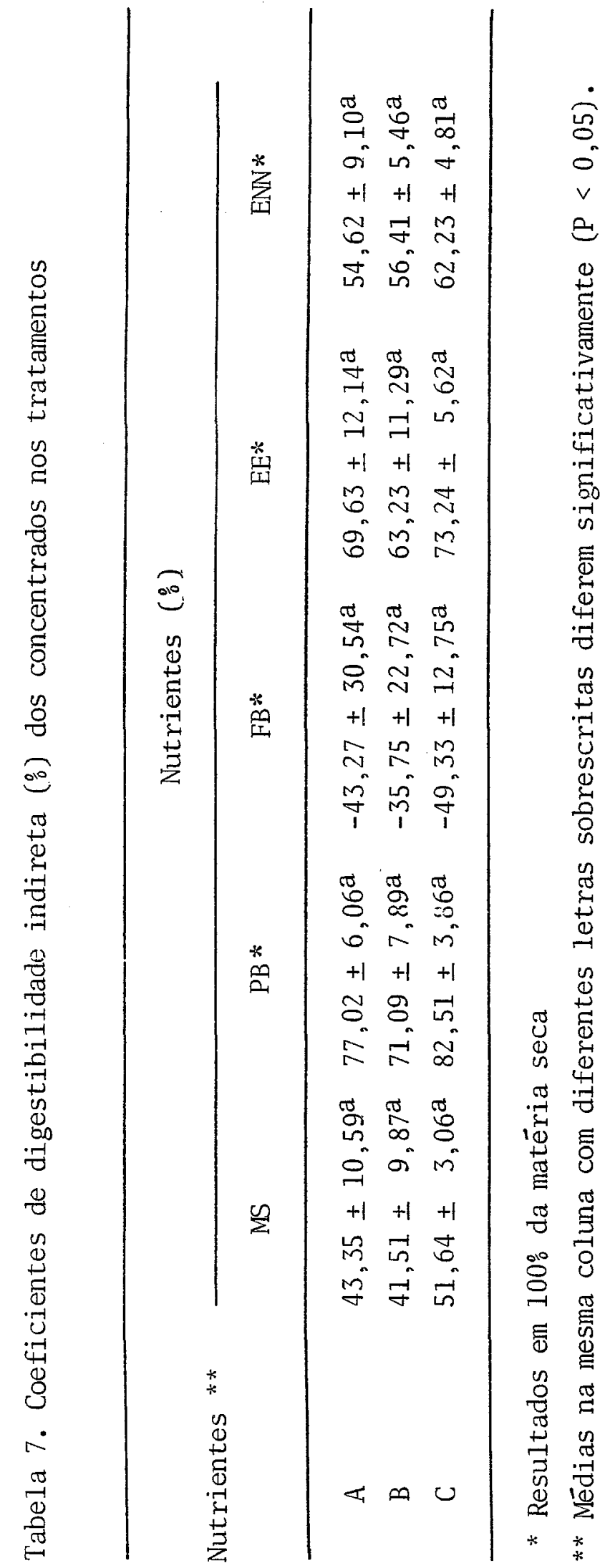




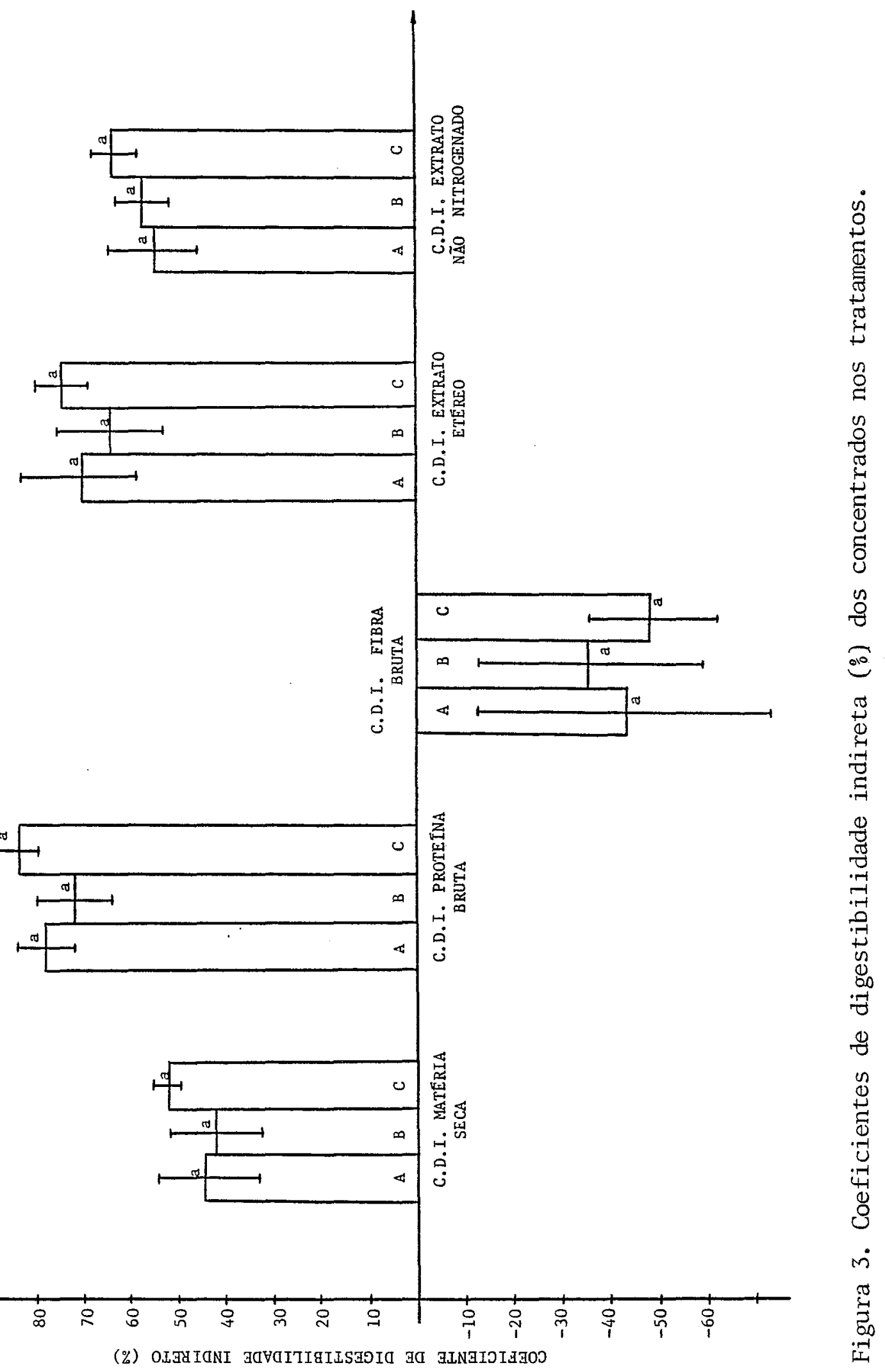


direta, resolvemos utilizä-1o por ser o processo que nos per mite avaliar os concentrados isoladamente.

SCHINEIDER \& FLATT (1975) relatam que um estudo do método de cálculo de D.I. mostra claramente que se houver qualquer efeito associativo, erro em amostragem, etc, quando a quantidade de um dos nutrientes em qualquer dos ali mentos é pequena em comparação com a quantidade do mesmo nutriente no outro alimento, as vezes resultados altamente divergentes podem ser obtidos. O erro seria maior quando a di gestibilidade de um concentrado é determinada desta forma e a proporção deste para o volumoso e pequena. Também aqueles nutrientes do concentrado que estão presentes em menor proporção, tal como FB e EE vão ser os mais afetados (ARSMBY, 1917; HAMILTON et alii, 1928). Por exemplo: se um alimento é adicionado a ração basal em tais proporção que sua proteína perfaça somente $5 \%$ de $P B$ total uma mudança de $1 \%$ na diges tibilidade de $\mathrm{PB}$ na ração basal resultară em uma mudança de aproximadamente $20 \%$ na digestibilidade aparente da PB do ali mento adicionado.

A determinação por diferença da digestibilidade aparente de alimentos concentrados que não podem ser fornecidos sozinhos pela adição deles como suplementos às rações basais, cuja digestibilidade foi determinada previamente tem as vezes produzido coeficientes que são tanto nega tivos quanto maiores do que 100. Alguns autores chamavam es tes coeficientes de digestibilidade menores de zero e aque- 
les acima de cem como absurdos ou fisiologicamente impossí veis. O autor não pode concluir de outra forma que não a de considerar os coeficientes de digestibilidade negativos e aqueles acima de cem como realidades que não podem ser ignoradas. Valores negativos e aqueles acima de $100 \%$ representam fenômenos encontrados na natureza e devem ser tratados como possibilidades razoāveis.

Dito por alguns pesquisadores que os valores impossiveis acima de cem ou menores que zero apresentam um problema quando se deseja calcular os NDT, isto é a soma de PB; FB; ENN; 2,25 x EE, a questio é feita. "Deve-se subtrair quando ocorre coeficiente negativo? Também deve-se adicionar mais que $100 \%$ de um nutriente"? A resposta para ambas perguntas é sim.

Embora coeficientes de digestibi'ilidade em média possam ser considerados representativos de respectivos alimentos, eles variam consideravelmente.

Com digestibilidade muito baixa esta variação em torno da mëdia pode resultar em alguns valores individuais negativos. Quando um nutriente existe num alimento em nível muito baixo, estes fenômenos podem simplesmente significar que a variação é muito maior que a quantidade do nutriente. No estudo da variação dos coeficientes de digestibilidade que são pröximos a zero deve-se esperar que alguns sejam negativos. Um alimento pode muito bem custar mais ao corpo do que ele contribui em termos de um determinado nutriente. De ou- 
tra forma, ele pode favorecer tanto os processos digestivos resultando na ração total (alimento adicionado mais alimento basal) muito mais de um nutriente em particular do que a quan tidade contida no alimento, quando a digestibilidade está sendo determinada por diferença.

Alguns autores obtiveram resultados que os le varam a concluir que forma física da ração ou dos alimentos, teve influência sobre seu aproveitamento pelos equinos. HINTZ \& LOY (1566) estudando a digestibilidade de uma ração comple ta nas formas peletizada e farelada em cinco pares de cavalos concluíram que o coeficiente de digestibilidade aparente do extrato etēreo foi significativamente maior para a ração peletizada

HAENLEIN et alii (1966) trabalhando com poneis com idade compreendida entre um e dois anos e cavalos adultos, avaliaram a resposta dos animais a três diferentes formas físicas (peletizada, "wafer" e farelada) de feno de alfafa e observaram que a digestibilidade da fibra bruta foi inferior na forma peletizada para os equinos. WOLTER et alii (1974) estudaram a influência da forma física da forragem na velocidade do trânsito digestivo em poneis com peso médio de $170 \mathrm{~kg}$. Os autores observaram diferenças significa tivas $(P<0,0.5)$ : entre as três formas de apresentação do feno sendo os tempos médios de retenção no trato digestivo de 37 horas, 31 horas e 26 horas para o feno normal, feno peletiza do e feno moido, respectivamente. WOLTER et alii (1975) es- 
tudaram a influência da forma física da forragem sobre a sua digestibilidade em equinos; os resultados encontrados mostra ram coeficientes de digestibilidade da MS e FB inferiores e diferentes significativamente em $(P<0,01)$ e $(P<0,05)$ das formas peletizada e moída em relação ao feno normal. Tambëm WOLTER et alii (1976) estudaram o efeito de formas fisicas de um alimento completo (farelado ümido; peletizado e extrudado) na velocidade de trânsido digestivo e digestibilidade em cinco poneis com peso médio de $197 \mathrm{~kg}$ e concluíram que: não houve diferença na velocidade do trânsito digestivo entre os tratamentos e que a digestibilidade aparente da MS do alimento extrudado foi significaticamente superior $(P<0,05)$ ao peletizado e ao farelado, não havendo diferença significa tiva para os demais nutrientes. WOLTER et alii (1978) avaliaram a digestibilidade aparente em poneis que recebiam 0 mesmo alimento nas formas peletizada, extrudada e semi-extrú dada (só a fração de cereais foi tratada). Os autores obse $\underline{r}$ varam que o alimento peletizado foi superior significativamen te aos outros para o aproveitamento de MS, jă para a PB tiveram equivalência entre o peletizado e semi-extrutado, com resultado inferior para o extrudado, porém para $F B$ a digestibilidade aparente foi superior no alimento semi - extrudado e se equivaleu para as outras formas.

WOLTER et alii (1980) trabalharam com poneis com fistulas duodenais que receberam o mesmo alimento peleti zado e semi-extrudado (só a porção de cereais recebe trata- 
mento). Os autores observaram que as formas físicas promoveram um aumento significativo nos coeficientes de digestibi lidade duodenal da MS, PB e amido sendo que o alimento semiextrudado apresentou valores superiores. RAINA \& RAGHAVAN (1985) trabalharam com cavalos adultos e compararam a mesma alimentação em arraçoamento tradicional, ração completa pele tizada e ração completa farelada. Os autores observaram uma melhora significativa dos coeficientes de digestibilidade apa rente da $P B$ e EE na dieta peletizada, jä ocorrendo o inverso para a fibra bruta.

LEWIS (1985) cita que a peletização aumenta a digestibilidade da PB em cereais, e tambëm o consumo de alimento e que os peletes são fäceis para serem fornecidos aos cavalos e diminuem as perdas em relação a alimentos farelados. Tamhêm cita como desvantagens da utilização as dietas peletizadas uma ocorrência de mastigação de madeira e um aumento no custo do alimento.

Outros autores, no entanto, obtiveram resulta dos que demonstraram não haver influência da forma física da ração ou dos alimentos sobre o aproveitamento dos mesmos pe los equinos como ocorreu no presente trabalho quando comparamos os coeficientes de digestibilidade indireta dos concen trados.

MANZANO (19.77) trabalhando com fêmeas em cres cimento da raça ārabe comparou um arraçoamento tradicional com uma ração completa peletizada e não encontrou diferenças sig 
nificativas entre os tratamentos. WOLTER et alii (1978) ava liando a digestibilidade aparente em poneis que recebiam o mesmo alimento nas formas peletizada, extrudada e semi-extru dada, apesar de encontrarem diferenças, concluiram que a for ma física do alimento tem pouca influência na digestibilidade aparente dos nutrientes. FORMENTINI et alii (1979) estudaram a viabilidade de utilização de rações completas peleti zada com cavalos adultos em trabalho e não foram encontradas quaisquer diferenças entre a ração tradicional e a peletizada na performance, exame clínico ou exame de laboratório nos animais utilizados. HAENLEIN (1980) relatol que a peletização não afeta muito a digestibilidade das rações de equiinos e que diferenças encontradas podem estar relacionadas com 0 aumento de consumo que ocorre com alimentos peletizados, jā que quando os niveis de consumo são restringidos no caso de fenos as digestibilidades dos nutrientes não peletizados e feno longo não são diferentes.

WOLTER et alii (1982) trabalhando com poneis que receberam, sucessivamente, quatro dietas a base de cereais nas formas: inteiro (integro), achatado, triturado e umidecido que tiveram a celulose ajustada com palha de trigo, concluíram que as formas físicas de apresentação dos al $\underline{i}$ mentos não alteraram a digestibilidade aparente dos mesmos e que tais processos só se justificariam para animais com prob.lemas de mastigação. 


\section{CONCLUSÕES}

Os resultados obtidos permitiram as seguintes conclusões:

1. Os resultados mostraram que a forma física dos concentrados não alterou a sua digestibilidade.

2. Os concentrados farelados produzidos na propriedade podem representar uma diminuição dos custos de prcdução, sem apresentar inconvenientes de ordem têcnica. 


\section{REFERÊNCIAS BIBLIOGRAFICAS}

ASSOCIATION OF OFFICIAL ANALYTICAL CHEMISTS. 11.ed. Washing ton, 1970. 1015p.

CRAMPTON, E.W. \& HARRIS, L.E. Applied Animal Nutrition. 2ed. San Francisco, W.H. Freeman, 1969. 753p.

ESCOLA SUPERIOR DE AGRICUltura "LUiz DE QUEIROZ". Comissão de Pós-Graduação. Normas para a elaboração de dissertações e teses. Piracicaba, 1987. 64p.

ESMINGER, M.E. Producion Equina. 3.ed. Buenos Aires. "E1 Ateneo", 1973. p.193-268.

EVANS, J.W.; BORTON, A.; HINTZ, H.F.; VAN VLECK, L.D. El Cabal10. Zaragoza, 1979. Ed. Acribia, 742p.

FORMENTINI, U.P.; SALA, A.; ARCHILEI, R. Esperimento di impiego di mangine completo pellettato su cavalli di alto pregio della Scuola Militare di Equitazione. Rivista di Zootecnia e Veterinaria, Milano, 3: 198-204, 1979.

HAENLEIN, G.F.W.; HOLDREN, R.D.; YOON, Y.M. Comparative res ponse of horses and sheep to different physical forms of alfafa hay. Journal of Animal Science, Albany, 25: 7403 , 1966 . 
HAENLEIN, G.F.W. Effect of processing on nutritive value of diets for horses. Landwortschaft1iche, Frankfurt, 33: 2$3,227-35,1980$.

HINTZ, H.F. \& LOY, R.G. Effects of pelleting on the nutriti ve value of horse rations. Journal of Animal Science, Al bany, 25: 1059-62, 1966.

LEWIS, L.D. Alimentação e cuidados do cavalo. São Paulo, Liv. Roca, 1985. $248 \mathrm{p}$.

MANZANo, A. Comparação entre ração completa peletizada e ar raçoamento tradicional na alimentação de equinos. Piracicaba, 19.77. 81p. Mestrado - Escola Superior de Agricultura "Luiz de Queiroz"/USP).

MAYNARD, L.A.; LOOSLI, J.K.; HINTZ, H.F.; WARNER, R.G. Animal Nutrition. 7.ed., New York, McGraw-Hi11, 1979. 602p.

NAGATA, Y.; MLRAKAMI, $\because$; ; SAKURAI, N. Effect of complete pelletized rations on the growth of race horses. Experimental Reports of Equine Health Laboratory, rokyo, 7 : $43-57,1970$.

NATIONAL RESEARCH COUNCIL. Nutrient Requirements of Horses. Washington, National Academy of Sciences, 1978. 33p. (Nutrient Requirements of Domestic Animals, 6).

OTT, E.A. References Issue, Nutrients Requirements of Horses. Feedstuffs, Mineapolis, 51: 67-74, 1979.

PIMENTEL GOMES, F. Curso de Estatística Experimental. 6.ed. Piracicaba, 1976. 430p. 
RAINA, I.N. \& RAGHAVAN, G.V. Processing of complete feeds and availability of nutrients to horses. Indian Journal of Animal Sciences, New Delhi, 55(4): 282-7, 1985.

SCHINEIDER, B.H. \& FLATT, W.P. The evaluation of feeds through digestibility experiments. Athens, University of Georgia Press, 1975. 423p.

SCHURG, W.A. \& PULSE, R.E. Grass straw an alternative roughage for horses. Journal of Animal Science, Albany, 38: 1330, 1974 .

SLADE, L.M. \& HINTZ, H.F. Comparison of digestion in horses, ponies, rabbits and guinea pigs. Journal of Animal Sciences, Albany, 28: 842-3, 1969 .

VEIGA, J.S.M.; ANDREASE, F.; PRADA, F.; MENDONÇA Jr., C. S. Digestibilidade aparente da matéria seca em equinos "1/2 sangue Bretão" e "1/2 sangue Inglês". Revista da Faculdade de Medicina, Veterinäria e Zootecnia, São Paulo, 11: 7-20, 1974 .

WOLTER, R.; DURIX, A.; LETOURNEAU, J.C. Influence du mode de prësentation du fourrage sur la vitesse du transit digestif chez le poney. Annales de Zootechinie, Paris, 23 (3): 29.3-300, 1974 .

WOLTER, R.; DURIX, A.; LETOURNEAU, J.C. Influence du mode de présentation du fourrage sur la digestibilité chez le poney. Annales de Zootechinie, Paris, 24(2): $237-42$, 1975.

WOLTER, R.; DURIX, A.; LEOURNEAU, J.C. Influence du mode de prësentation d'un aliment complet sur la vitesse du tran sit digestif et la digestibilite chez le poney. Annales de Zootechinie, Paris, 25(2): 181-8, 1976. 
WOLTER, R.; GOUY, D.; DURIX, A.; LetOURNEAU, J.C. ; CARCELEN, M.; LANDREAU, J. Digestibilité et activitë biochimique intra caecal chez le poney recevant um même aliment complet pre senté sous forme granulée, expansēe ou semi-expansée. Annalles de Zootechinie, Paris, 27(1): 47-60, 1978.

WOLTER, R.; DURIX, A.; GOUY, D.; LETOURNEAU, J.C.; CARCELEN, M.; GOUY, J. Paramëtris biochimiques et digestibilite dans le duedenum chez le poneu relevant un même aliment complet ou semi expansi. Annales de Zootechinie, Paris, 29 (3): $305-315, \quad 1980$.

WOLTER, R.; VALETTE, J.P.; DURIX, A.; LETOURNEAU, J.C.; CARCELEN, M. Digestibilité comparëe de quatre céréales (avoine, or ge, mais, blë) selon le mode de présentation chez le poney. Annales de Zootechinie, Paris, 3I(4): 445-57, 1982. 